\title{
Amphipathic environments for determining the structure of membrane proteins by single-particle electron cryo-microscopy.
}

\author{
Christel Le Bon ${ }^{1,2}$, Baptiste Michon ${ }^{1,2}$, Jean-Luc Popot ${ }^{1,2}$, Manuela Zoonens ${ }^{1,2 *}$ \\ ${ }^{1}$ Université de Paris, Laboratoire de Biologie Physico-Chimique des Protéines Membranaires, CNRS, UMR 7099, F-75005 \\ Paris, France \\ ${ }^{2}$ Institut de Biologie Physico-Chimique, Fondation Edmond de Rothschild pour le développement de la recherche Scienti- \\ fique, F-75005 Paris, France
}

*Correspondence should be addressed to Manuela Zoonens (manuela.zoonens@ibpc.fr)

KEYWORDS: amphipols, detergents, integral membrane protein complexes, lipids, nanodiscs, structural biology.

ABSTRACT: Over the past decade, the structural biology of membrane proteins (MPs) has taken a new turn thanks to epoch-making technical progress in single-particle electron cryo-microscopy (cryo-EM) as well as to improvements in sample preparation. The present analysis provides an overview of the extent and modes of usage of the various types of surfactants for cryo-EM studies. Digitonin, dodecylmaltoside, protein-based nanodiscs, lauryl maltoside-neopentyl glycol, glyco-diosgenin and amphipols are the most popular surfactants at the vitrification step. Surfactant exchange is frequently used between MP purification and grid preparation, requiring extensive optimization each time the study of a new MP is undertaken. The variety of both the surfactants and experimental approaches used over the past few years bears witness to the need to continue developing innovative surfactants and optimizing conditions for sample preparation. The possibilities offered by novel amphipols for EM applications are discussed.

\section{Introduction}

Membrane proteins (MPs) fulfill essential biological functions in the cell and are important biomedical targets. Obtaining MP high-resolution structures can contribute tremendously to the development of novel therapies. However, structural studies of MPs are notoriously more challenging than those of soluble proteins. Many difficulties affect all steps of sample preparation from protein expression to structural determination. Extraction from the native lipid environment with and stabilization against surfactants are particularly critical steps, whose optimization is time-consuming. Over the years, many strategies and tools have been developed to overcome each type of difficulty.

The first MPs for which atomic models could be built were proteins that are naturally abundant (Deisenhofer et al., 1985; Weiss et al., 1990; Henderson et al., 1990). However, the low natural abundance of most MPs necessitated the development of recombinant expression strategies in either microbial host cells, such as Escherichia coli or Saccharomyces cerevisiae (Hays et al., 2010; Zoonens and Miroux, 2010; Dilworth et al., 2018), or other expression systems better suited to the production of mammalian MPs, such as baculovirus-infected insect cells or human embryo kidney (HEK) cells (Bill et al., 2011; Andréll and Tate, 2013; Contreras-Gómez et al., 2014). These host cells have proven very efficient for producing MPs in amounts amenable to structural investigations.

Once they are expressed in suitable quantities, MPs need to be extracted from the membrane and purified in their native state. Unfortunately, their stability in aqueous solutions is often problematic. Perturbation of the protein structure by inadequate surfactants can generate misleading data (Cross et al., 2011; Chipot et al., 2018), which is a major concern in this field. Detergents are historically the first surfactants used for MP solubilization and purification. Detergents disrupt the membrane and adsorb onto the hydrophobic transmembrane surface of MPs, keeping them water-soluble (see e.g. (Garavito and Ferguson-Miller, 2001; Otzen, 2015; Sadaf et al., 2015; OrwickRydmark et al., 2016; Popot, 2018)). However, detergents tend to interfere with molecular interactions in MP transmembrane domains, leading to inactivation (for a recent discussion of causes and remedies, see Chapter 2 in ref. (Popot, 2018)). The extent of this problem varies both from one detergent and from one MP to another. Quite naturally, the first high-resolution structures of MPs ever obtained were those of abundant and detergent-resistant bacterial MPs. Access to the structures of generally more fragile and less abundant eukaryotic MPs has been made possible by progress in production methods, technical advances in structural approaches, and the development and increasingly frequent usage of novel, less destabilizing surfactants. Detergents and other emerging tools used to prepare MP samples for structural determination by single-particle electron cryo-microscopy (SP cryo-EM) have been described in refs. (Mio and Sato, 2018; Autzen et al., 2019).

In the present review, we have carried out a quantitative analysis, for all cryo-EM structures of MPs deposited as of January $1^{\text {st }}, 2021$, of the use of detergents, amphipathic polymers such as amphipols (APols) and styrene-maleic acid (SMA) copolymers, protein-based nanodiscs (NDs), and other emerging compounds. The analysis is based on the list of MP 
structures available on Stephen White's database (https://blanco.biomol.uci.edu/mpstruc/), which is designed to be as inclusive as possible. This list contains all unique MP structures, coordinate files, and almost all published reports of MP structures accumulated in the protein data bank (PDB) since 1985. The goal of the present analysis is to give an overview of the evolution of approaches in this rapidly moving field and, more specifically, of current trends in the implementation of conventional and novel surfactants. Recently, a similar analysis has been performed (Choy et al., 2021), which includes structures obtained by X-ray crystallography and NMR but bears on a more restricted corpus of cryo-EM data (see below).

\section{The cryo-EM resolution revolution and its impact on MP structural biology}

Approaches giving access to the three-dimensional (3D) structure of biological macromolecules include X-ray crystallography, solution and solid-state NMR spectroscopy, electron crystallography and SP cryo-EM. The distribution of the unique MP structures published during each of the past 35 years, sorted out according to the structural approach used, is shown in Figure 1A. Over three decades, X-ray crystallography was the dominant technique in MP structural biology. As a result, more than two thirds of the total number of currently available unique MP structures have been solved using this approach (Figure 1B). X-ray crystallography can reveal atomic details of MP structure at a very high resolution. Its major bottleneck remains the production of well-ordered 3D crystals. This is particularly challenging for MPs due to the presence of detergent, instability, and/or intrinsic conformational heterogeneity (Tate, 2010). Significant progress has been achieved by resorting to strategies such as the binding of antibody fragments or nanobodies, MP stabilization through engineered mutations, the use of lipidic cubic phases, and/or novel techniques for collecting diffraction data, such as the use of micrometric synchrotron $\mathrm{X}$-ray beams and X-ray free-electron lasers (for reviews, see e.g. (Martin-Garcia et al., 2016; Ishchenko et al., 2017)). Over the past decade, however, the most spectacular breakthroughs have been achieved in cryo-EM (Nogales and Scheres, 2015; Vinothkumar and Henderson, 2016; De Zorzi et al., 2016; Cheng, 2018; Nwanochie and Uversky, 2019).

Cryo-EM encompasses a variety of techniques for determining the structures of frozen-hydrated samples, which are based on the analysis of $i$ ) images of single particles of purified biomolecules; ii) images and diffraction patterns of crystalline arrays; and iii) images of whole cells or cell sections (tomography). In electron cryo-tomography, although important biological insights can be gained from images of biomolecules within their native environment, the resolution is generally much lower than that achieved with the two other cryo-EM techniques, i.e. electron crystallography and SP analysis, from which structural data at near-atomic resolution can be obtained. Electron crystallography is typically applied to planar or tubular two-dimensional (2D) crystals (Abeyrathne et al., 2012; Kühlbrandt, 2013). A more recent technique, referred to as microcrystal electron diffraction (MicroED), has been developed for the analysis of 3D microcrystals (Nannenga and Gonen, 2019; Nguyen and Gonen, 2020); for the moment, however, microED has not yet yielded any de novo MP structure.

Electron crystallography applied to $2 \mathrm{D}$ crystals has a long and prestigious history, as it was the approach that enabled

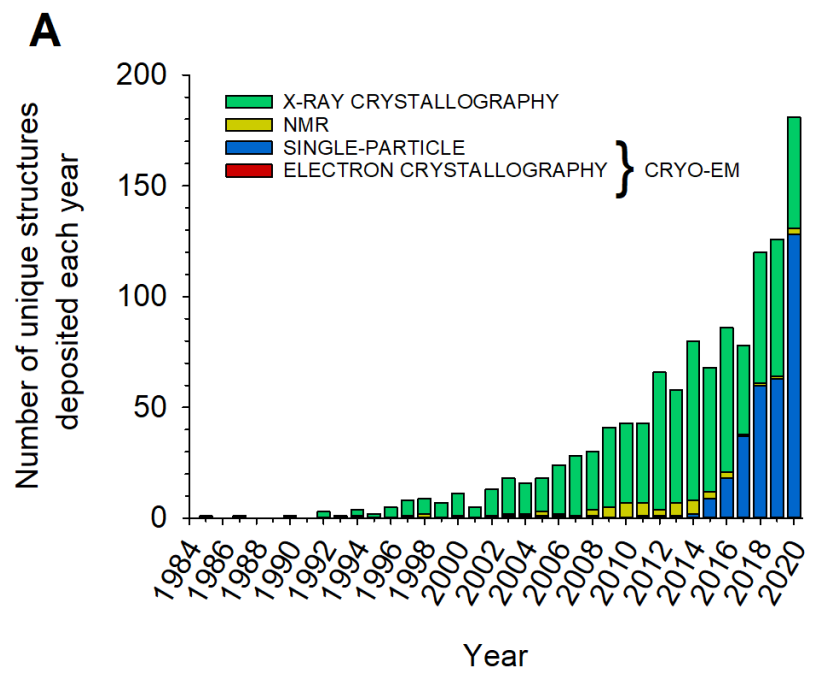

B

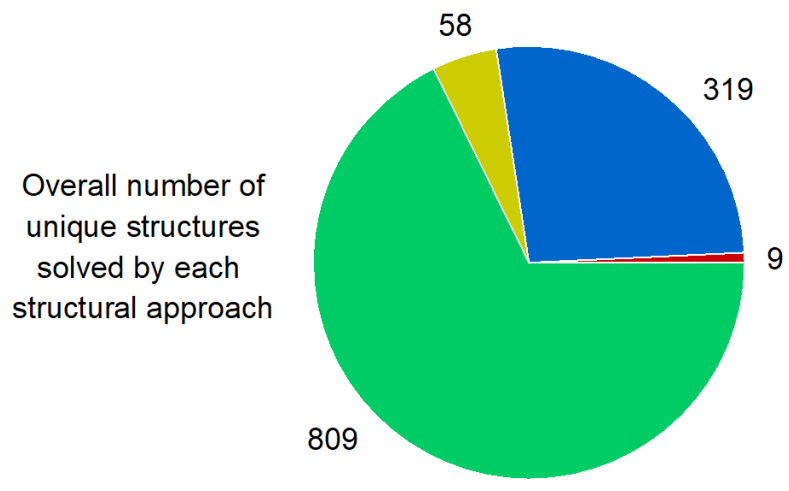

Figure 1. Distribution of unique MP structures solved by each structural approach between 1985 and January 1st, 2021. (A) Number of unique MP structures deposited each year using each approach. (B) Distribution of the 1195 unique structures extracted from Stephen White's database (https://blanco.biomol.uci.edu/mpstruc/) according to the approach used to solve them. The figures were prepared using the January $8^{\text {th }}, 2021$, update of MP structures from this database. Some MP structures published in 2020 may therefore not be included.

building the first medium-resolution structural model ever obtained of a MP, that of the archaebacterial bacteriorhodopsin (at 7- $\AA$ resolution in the membrane plane (Henderson and Unwin, 1975)), and, later, yielded the first data (at $3.5 \AA$ in-plane) leading to an atomic model of the protein's transmembrane region (Henderson et al., 1990). Before 2013, deposited cryo-EM coordinates of MPs were all from 2D crystal electron crystallography. In 2013 were published the first near-atomic-resolution MP structures determined by SP cryo-EM (Cao et al., 2013; Liao et al., 2013). Since that date, the number of unique MP structures established by this approach has increased explosively (Figure 1A). Decisive advances, particularly as regards data collection and correction, as well as software development for model building, have revolutionized the field (Cheng, 2015; Alnabati and Kihara, 2019). A combined approach of SP analysis applied to helical arrays (McCullough et al., 2015; LopezRedondo et al., 2018) or 2D crystals (Righetto et al., 2019) has been reported. As a rule, however, SP analysis in cryo-EM refers to images of solubilized, unstained, isolated MPs embedded 
in a thin layer of vitreous ice, which are classified and averaged for $3 \mathrm{D}$ reconstruction.

Because it bypasses crystallization, which is the limiting step in X-ray and electron crystallography, SP cryo-EM has turned into a highly efficient approach to structural analysis of MPs, to the point that three quarters of the MP structures determined in 2020 have been obtained in this way (Figure 1A). However, whereas both crystallography and NMR can solve the structures of small MPs, a size limit (currently $100 \mathrm{kDa}$; see (Nygaard et al., 2020)) exists in SP cryo-EM because, if a MP is too small, aligning particle images becomes difficult (Henderson, 1995). Given that the technique is evolving rapidly, one can expect to reach in a near future a size limit close to $\sim 40 \mathrm{kDa}$, as for soluble proteins (Zubcevic et al., 2016). Alternatively, the size of small MPs can be artificially increased by binding either a natural (Frauenfeld et al., 2011) or an artificial ligand (Wu et al., 2012), provided that the assembly is well-defined and rigid. This strategy has been widely employed for determining the cryo-EM structures of $G$ protein-coupled receptors (GPCRs) in complex with either their natural $\mathrm{G}$ protein or arrestin ligands (Liang et al., 2017; Draper-Joyce et al., 2018; Zhao et al., 2019c; Huang et al., 2020a), an antibody fragment (Fab) and/or a nanobody (Zhao et al., 2019a; Tsutsumi et al., 2020), or a combination of these ligands (Gao et al., 2019; Yin et al., 2019a; Tsai et al., 2019; Nguyen et al., 2019; Ma et al., 2020; Qiao et al., 2020). More recently, another class of chimeric binders, called megabodies, consisting in a nanobody grafted onto a larger scaffold protein via two short peptide linkers, has been engineered to overcome size limitations while improving the particle orientation in ice (Uchański et al., 2021).

Structural studies of eukaryotic MPs have strongly benefited from progresses in SP cryo-EM, to the point that currently $\sim 76 \%$ of the unique MP structures solved by this technique are those of eukaryotic MPs, vs. $35 \%$ of those solved by $\mathrm{X}$-ray crystallography (Figure 2A). Among eukaryotic cryoEM MP structures, mammalian proteins represent $\sim 68 \%$, an evolution that also reflects recent progresses in expression strategies (Figure 2B). Challenging protein complexes whose structural determination was not technically possible ten years ago are now accessible. The distribution of structures obtained by cryo-EM is overwhelmingly in favor of integral MPs with $\alpha$ helical $(89 \%)$ rather than $\beta$-barrel transmembrane domains $(\sim 9 \%)$, whereas monotopic MPs represent $\sim 2 \%$. The main subgroups of $\alpha$-helical MPs are channels, ATP Binding Cassette (ABC) transporters, electron transport chain supercomplexes, GPCRs, and ATPases (Figure 3A), secretion complexes constituting the main subgroup of $\beta$-barrel MPs (Figure 3B).

The resolutions achieved using SP cryo-EM keep improving from year to year. In 2018, the structure with the highest resolution was that of a voltage-gated sodium channel, obtained at $2.8-\AA$ resolution when bound to the gating modifier toxin Dc1a (PDB accession code: 6 A90) and at 2.6- $\AA$ resolution in the presence of the pore blocker tetrodotoxin (PDB accession code: 6A95) (Shen et al., 2018). In 2019, a resolution of $2.37 \AA$ was achieved for the structure of tetrameric Photosystem I (PDB accession code: 6K61) (Zheng et al., 2019). Finally, in 2020 , the threshold of $2-\AA$ resolution was crossed with the structure of the sheep connexin- 46 solved at $1.9 \AA$ (PDB accession code: 7JKC) (Flores et al., 2020) and that of a homopentameric $\beta 3 \quad \gamma$-aminobutyric acid type-A receptor
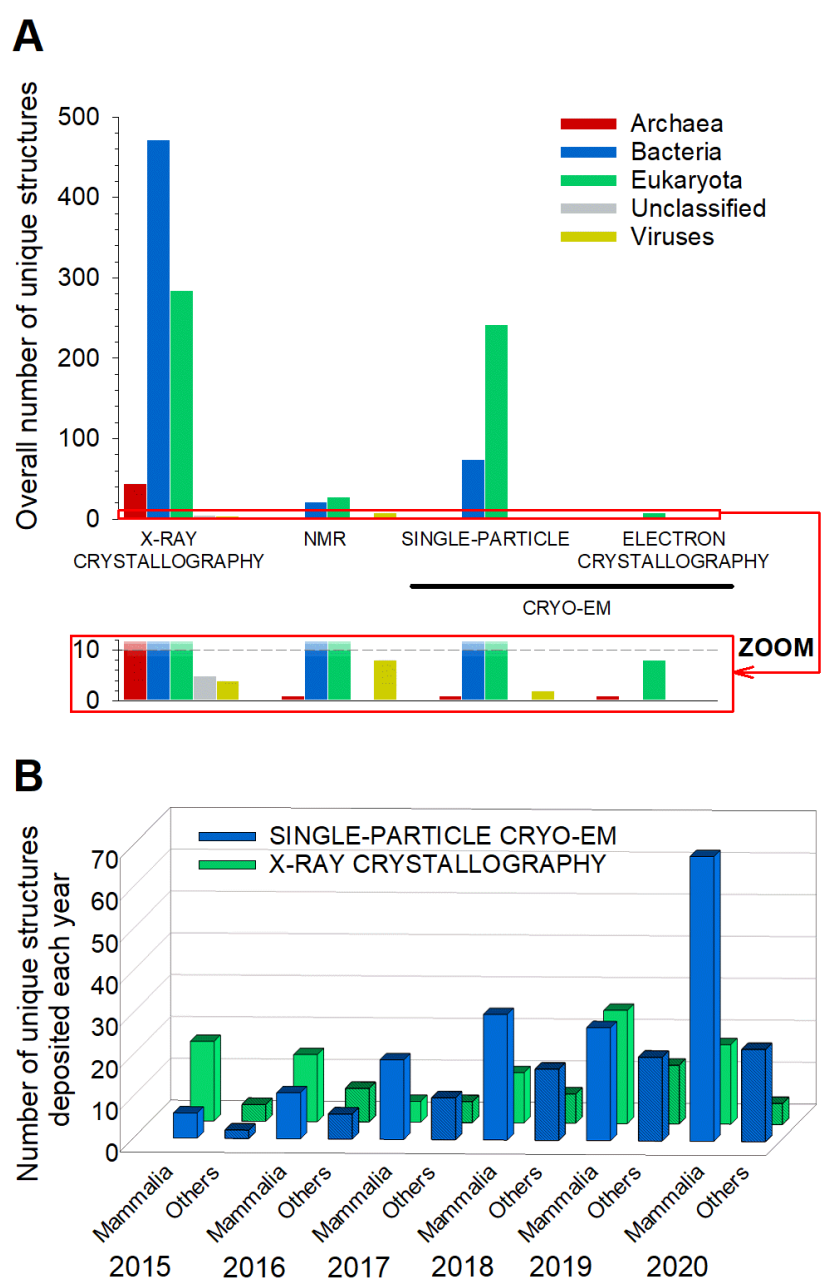

Figure 2. Distribution of unique MP structures according to biological origin. (A) Unique MP structures were classified into five groups (archaea, bacteria, eukaryotes, viruses and unclassified). The latter group comprises four crystallographic structures of de novo designed MPs. (B) Repartition of mammalian $v s$. other eukaryotic MP structures solved by either SP cryo-EM or X-ray crystallography over the past 6 years.

solved at $1.7 \AA$ (PDB accession code: 7A5V) (Nakane et al., 2020).

Despite this dramatic progress in improving the resolution of SP cryo-EM data, one should keep in mind that many of the atomic models reported in the PDB have benefited from docking high-resolution structures derived from X-ray crystallography, NMR spectroscopy or other cryo-EM studies as initial templates into cryo-EM maps. Structures of soluble extramembrane domains or homologous proteins from different species are often used. Rigid or flexible fitting methods are commonly applied for the validation and interpretation of cryo-EM structures (compared to rigid fitting methods, flexible ones allow conformational changes that improve fitting the model into the experimental map). Many atomic models derived from cryo-EM result therefore from a mix between these different approaches rather than being fully $a b$ initio structures. The higher the resolution achieved, of course, the safer is the resulting model, which is a strong incentive to improving the quality of experimental data. Which biochemical approaches are being developed to this end is the main subject of this review. 
A

$\alpha$-Helical membrane proteins

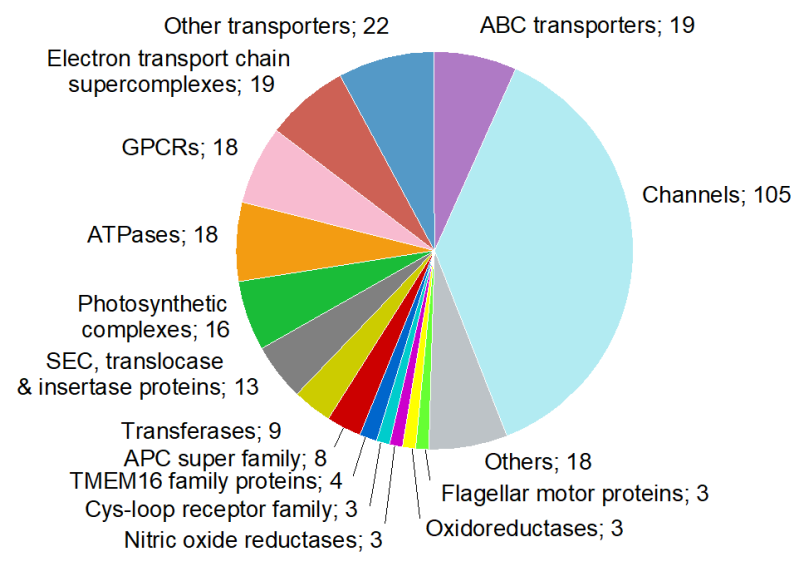

B

$\beta$-Barrel membrane proteins

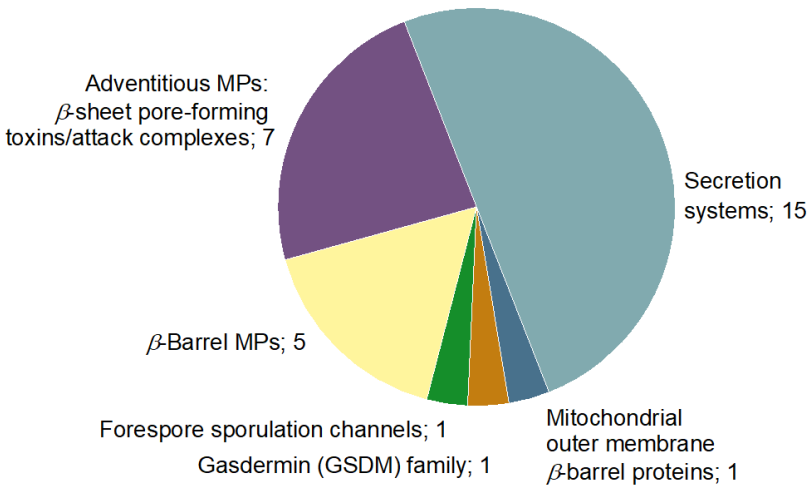

Figure 3. Family distribution of unique MP structures solved by SP cryo-EM. The groups of (A) $\alpha$-helical and (B) $\beta$-barrel MPs gather 281 and 30 unique MP structures, respectively. "Others", in the $\alpha$-helical MP group, refers to cryo-EM structures of MPs belonging to the membrane-spanning 4-domain (MS4) family, antiporters, cellulose synthases, sterol-sensing domain (SDD) proteins, Type VII secretion systems, intramembrane proteases, adventitious MPs ( $\alpha$-helical pore-forming toxins), host-defense proteins, decarboxylases, novel receptors (STRA6 retinol-uptake receptor in complex with calmodulin), transhydrogenases, adenylyl cyclases, chain length determinant proteins and glycoproteins. "Other transporters" gather one cryo-EM structure of drug/metabolite transporter, two structures of $\mathrm{H}^{+} / \mathrm{Cl}^{-}$or $\mathrm{F}^{-}$exchange transporters, two structures of transporters belonging to the major facilitator superfamily (MFS), three structures of multi-drug efflux transporters and, finally, fourteen structures of MPs belonging to the solute carrier (SLC) transporter superfamily.

\section{Selection of reports}

Despite technical advances, substantial barriers still stand in the way of many cryo-EM projects. Obtaining cryo-EM grids of sufficient quality for high-resolution structural analysis is not a trivial task. There is no unique answer to the question, "Which detergent or detergent substitute is the most appropriate for MP structural determination by SP cryo-EM?" In any study, the final choice of the surfactant(s) in which the structure will be determined depends not only on the target MP, but also on the relative amount of efforts invested optimizing one or another set of experimental conditions. A surfactant that appeared inferior in a first study can thus provide superior results in another. For instance, it was initially observed that the human $\gamma$-secretase yielded a higher-resolution cryo-EM structure in APol A8-35 than in digitonin (Lu et al., 2014), whereas, a few years later, using a version of $\gamma$-secretase fused with T4 lysozyme, two other structures were obtained in digitonin at a higher resolution than that initially achieved in A8-35 (Yang et al., 2019; Zhou et al., 2019). Beyond some obvious limitations, such as the fact that current membrane scaffold protein (MSP)based NDs (Denisov and Sligar, 2017; Sligar and Denisov, 2020) cannot accommodate MPs with very large transmembrane domains and thus are not appropriate for studying large supercomplexes (see below), trial-and-error is still the only way to proceed. Yet, examining the set of all MP structures determined to-date by SP cryo-EM reveals some interesting trends that can help selecting the most promising tools.

Analyzing unique MP structures provides an overview of the types of structures solved and their biological origin. Based on this dataset, an analysis of the surfactants used for solubilization and structure determination of MPs (whatever the structural approach used) has been recently published (Choy et al., 2021). However, the structure of a given MP has often been published more than once, generating several PDB files for the same protein. In the present study, we chose to include all of these data, hereafter called "published reports". This raises the number of experimental situations from 1195 unique structures to 2212 published reports (Figure 4). As regards cryo-EM alone (including both SP and electron crystallography), this number increases from 328 unique structures (187 in (Choy et al., 2021)) to 616 reports, thus providing a more exhaustive view of the extent to which each type of surfactant is used. Most of the structures have been obtained by SP cryo-EM analysis (316 unique MP structures, 587 reports). The number of $\alpha$-helical MPs almost doubles, with 536 reports vs. 281 unique structures (six reports missing from S. White's database have been included in the list (Wang and Sigworth, 2009; Yao et al., 2020; Hua et al., 2020; Zhang et al., 2020; Glavier et al., 2020; McDowell et al., 2020)). Here again, the most representative subgroups include channels, ABC transporters, electron transport chain supercomplexes, ATPases, and GPCRs. The latter comprise 67 structures overall for only 18 unique ones. The resolution of the vast majority of structures reported lies between 2 and $5 \AA$ (554 over 593 files, i.e. > $90 \%)$, with a median around 3.4-3.5 $\AA$. Knowing that the resolution of cryo-EM maps is usually not uniform due to protein flexibility and dynamics, which tend to degrade the resolution at the periphery of the protein as compared to its core, the resolution value is usually given on an indicative basis. Somewhat arbitrarily, a threshold of 5-Å resolution (sufficient to fit $\alpha$-helices into EM maps) was chosen for a structure to be included in our analysis, the aim being to obtain as broad an overview as possible of the diversity of surfactants that can be used to achieve near-atomic resolution, while leaving aside those that have not yet proven up to this task. In certain studies, SP cryo-EM analysis of a given MP was performed in two or three distinct environments, leading to the refinement of several models deposited in the PDB. This is a very interesting situation, whose lessons will be discussed below. To obtain the widest possible view of all usable environments, such "duplicate" structures have been included when appropriate (that is, whenever several distinct structures have been deposited in the PDB and/or the electron microscopy data bank (EMDB)), increasing the number of experimental situations that have yielded $2-5-\AA$ resolution structures from 554 to 604 (Figure 4). 


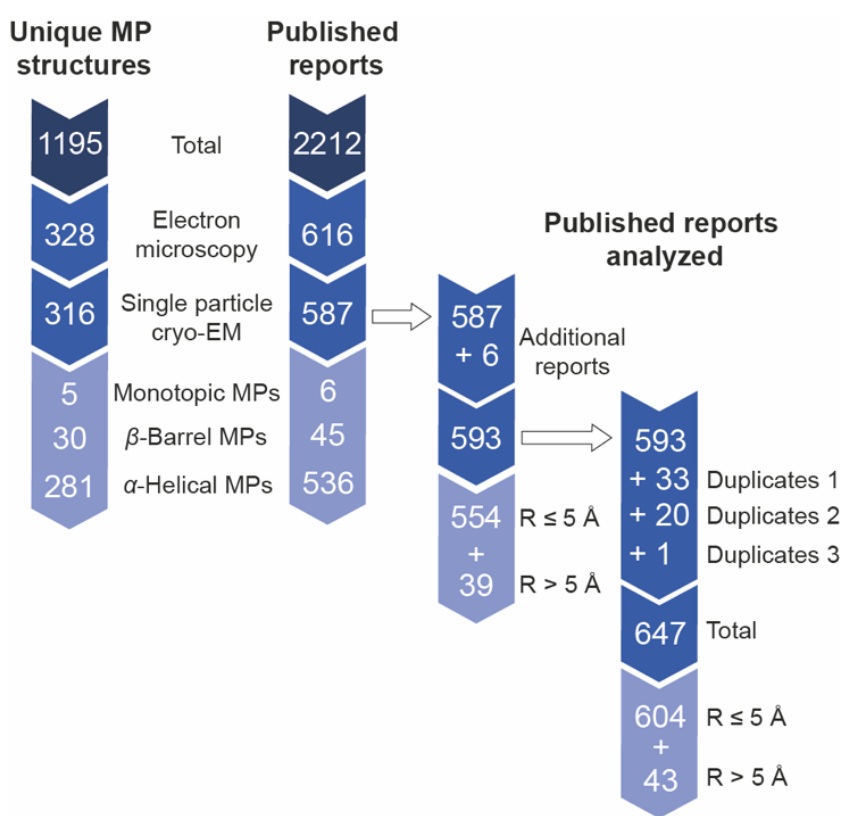

Figure 4. Number of unique cryo-EM MP structures and published reports analyzed in this study. Among the cryo-EM structures, SP analysis is the predominant technique, only nine unique MP structures having been solved using electron crystallography. Most cryo-EM MP structures have been solved by SP analysis applied to images of isolated MPs embedded in vitreous ice, one and two structures having been obtained by SP analysis applied to 2D crystals and helical assemblies, respectively. The list of reports analyzed comes from Stephen White's database, manually completed with sixty SP cryo-EM structures for which a PDB and/or EMDB accession number was available (see below). Two cryo-EM structures of MPs reconstituted into liposomes have been included. In addition, examination of each of the 587 studies revealed that some cryo-EM structures were missing. They have been manually integrated into the list of reports as follows: $a$ ) in four studies, an additional cryo-EM structure of a distinct MP or MP complex was identified and added to the list of reports, $b$ ) in 50 studies, a 3D reconstruction of a MP has been obtained in two different surfactants, yielding two distinct refined structures, generating two sets of experimental conditions that have been included in our analysis as "duplicates", and $c$ ) in 2 studies, the cryo-EM structure of a MP has been obtained in three different surfactants, yielding "triplicates". These additional experimental conditions were gathered in three groups: "Duplicates 1": distinct cryo-EM structures were obtained in two (or three) different surfactants, whereas the detergent used for the purification was unchanged; "Duplicates 2": both the purification and vitrification surfactants differed; "Duplicates 3": the vitrification surfactant was the same but the purification was performed in two distinct detergents.

\section{An overview of surfactant usage at the vitrification step}

Among SP cryo-EM structures obtained at a resolution of $5 \AA$ or better (hereafter noted $\leq 5 \AA$ ), the six surfactants most frequently used for vitrification are, in order of decreasing frequency of use, 1) digitonin, 2) detergents with a single maltose-based polar moiety and a single alkyl chain (mostly $n$-dodecyl- $\alpha$ - (or $\beta$-) D-maltoside (DDM), occasionally undecyl- or decyl-maltoside (resp. UDM and DM)), 3) MSP-based NDs, 4) detergents belonging to the maltoside-neopentyl glycol (MNG) family, which feature two maltose-based polar heads and two alkyl chains, 5) glyco-diosgenin (GDN), and 6) classical APols (mainly A8-35 and PMAL-C8) (Figures 5-7).

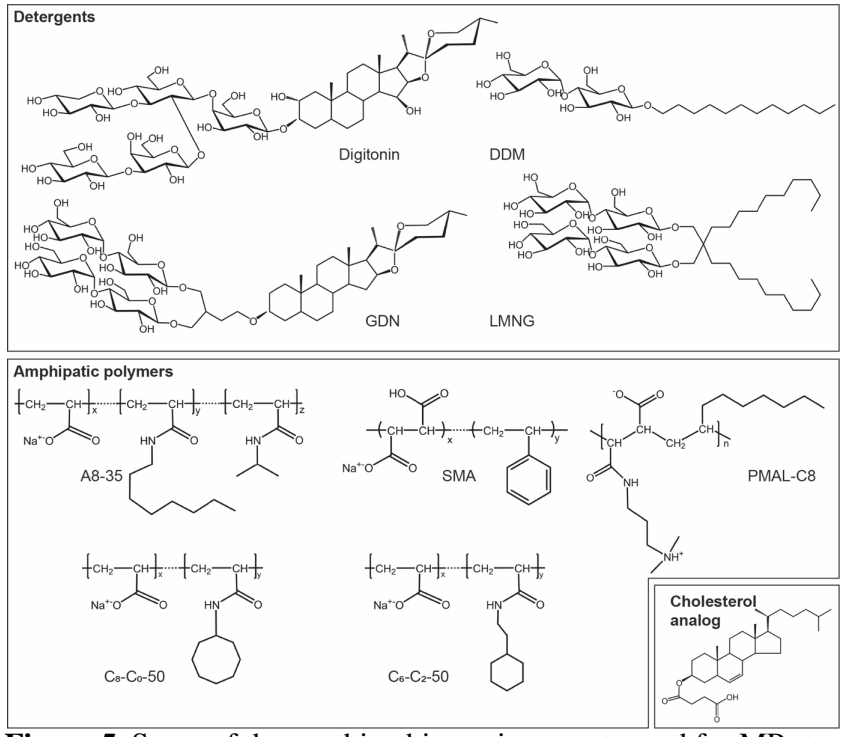

Figure 5. Some of the amphipathic environments used for MP stabilization. Chemical structures of detergents: digitonin, glyco-diosgenin (GDN), $n$-dodecyl- $\beta$-D-maltoside (DDM) and Lauryl Maltoside-Neopentyl Glycol (LMNG); APols: A8-35, PMAL-C8, SMA, and CyclAPols $\mathrm{C}_{8}-\mathrm{C}_{0}-50$ and $\mathrm{C}_{6}-\mathrm{C}_{2}-50$; hydrosoluble cholesterol analog: cholesteryl hemisuccinate (CHS).

Digitonin, the most popular surfactant, was used for $\sim 18 \%$ of MP structures determined at resolutions $\leq 5 \AA$ (Figure 7A). This natural detergent is a pentasaccharide derivative of steroidal aglycon digitogenin, produced by the purple foxglove (Digitalis purpurea) (Figure 5). Commercial digitonin is in fact a mixture consisting of about five glycosides, the main components of this mixture being digitonin and digalonin, a saponin of similar structure, in which the 2-hydroxy digitogenin is missing (Fukunaga et al., 1988). Commercial preparations of digitonin cannot be used directly, because even the best preparations contain 30-50\% w/w of material that cannot be dispersed evenly in water, and the effects of unpurified digitonin are unpredictable. Therefore, purification of commercial digitonin by recrystallization is recommended (Kun et al., 1979). Whereas digitonin presents quite a few drawbacks, such as batch-tobatch variations, formation of large micelles, crystallization at low temperature and ill-defined critical micellar concentration $(\mathrm{CMC}<0.5 \mathrm{mM})$, it is widely used in cryo-EM due to its mildness. Glyco-diosgenin (GDN) is a recent synthetic detergent (Chae et al., 2012), whose chemical structure mimics that of digitonin (Figure 5). Due to its homogeneity, the CMC of GDN, which is very low $(\sim 18 \mu \mathrm{M})$, is better defined than that digitonin (Chae et al., 2012). SP cryo-EM structures of GDNsolubilized MPs appeared for the first time in 2017. Three years later, its use is reported more often than that of digitonin (in 41 structures vs. 33 for digitonin) (Figure 7B).

The second most widely used surfactants in cryo-EM are maltoside detergents such as DDM, UDM and DM, with a clear preference for DDM (86 structures out of 103). DDM (Figure 5) was developed in the mid '70s-early ' 80 s (Rosevear et al., 1980) and has been widely used in X-ray crystallography (Dilworth et al., 2018; Choy et al., 2021). The polar head of DDM, UDM and DM is provided by a disaccharide (maltose), whereas the hydrophobic parts are 12-, 11-, and 10-carbon $n$-alkyl chains, respectively. The CMC value of DDM is low $(\sim 0.17$ $\mathrm{mM}$ for $\beta$-DDM) and it forms well-defined micelles; UDM and $\mathrm{DM}$ have higher $\mathrm{CMC}$ values $(0.59 \mathrm{mM}$ and $1.8 \mathrm{mM}$, 
respectively) ((Bhairi and Mohan, 2007; Stetsenko and Guskov, 2017) and see Table 2 in ref. (Abeyrathne et al., 2012)).

MNG detergents were synthesized and initially used mainly for GPCR crystallization (Chae et al., 2010). These molecules carry two alkyl chains and two hydrophilic groups derived from maltose, linked via a central quaternary carbon atom (Figure 5). Because of the presence of two long alkyl chains, MNGs have very low CMCs (e.g. $\sim 10 \mu \mathrm{M}$ for LMNG, which is by far the most widely used MNG, with 73 structures out of 75). While MNGs appear only at the fourth position of the most frequently used surfactants, with an overall frequency of $\sim 12 \%$ (Figure 7A), they represent one of the surfactant classes most frequently used in 2020 (Figure 7B), partly due to their use for solving GPCR structures.

The third and sixth most often used surfactant classes are, respectively, protein-based NDs and amphipathic polymers called amphipols (APols), both developed in the '90s. These two detergent substitutes are structurally very different, but both aim at solving the problem of detergent-induced MP instability by eliminating the detergent altogether.

APols constitute a family of short and flexible amphipathic polymers specially developed for MP biochemistry (Tribet et al., 1996; Popot et al., 2011; Zoonens and Popot, 2014; Popot, 2018) (Figure 5). For a long time, when X-ray crystallography was the predominant technique in MP structural biology, APols were considered relatively unattractive. This was due to the mistaken view that the use of polydisperse molecules would hinder crystallization. This point is not necessarily relevant, given that most of the molecules comprising the surfactant belt are disordered anyway (for discussions, see (Charvolin et al., 2014), and Chapter 11 in ref. (Popot, 2018)). Indeed, a recent study has shown that a mix of DDM and A835 (the latter used as a stabilizing agent) allows one to solve the $\mathrm{X}$-ray structure of herpes simplex virus glycoprotein B at higher resolution than can be achieved with DDM alone (Cooper et al., 2018; Cooper and Heldwein, 2020). More to the point is the fact that early APols carried charged polar moieties, which tend to hamper 3D crystallization, whereas non-ionic APols (NAPols) (Bazzacco et al., 2012) have only recently become commercially available. The use of APols has been reported in $>100$ EM studies (those published from 1998 until late 2017 are reviewed in Chapter 12 of ref. (Popot, 2018)). In the present analysis, only the cryo-EM structures of APol-complexed MPs included in Stephen White's database with resolutions $\leq 5 \AA$ A have been taken into consideration. Out of 60 cryo-EM MP structures determined using APols, 34 were obtained in A8-35 (Tribet et al., 1996) (Figure 5) and 19 in PMAL-C8 (Nagy et al., 2001) (Figure 5). A8-35 first left its mark in SP cryo-EM with the lowresolution structure (at $\sim 19 \AA$ ) of a mammalian MP supercomplex, that of the bovine mitochondrial respirasome (Althoff et al., 2011). It also led to the first near-atomic resolution structures (at 3.8 and $3.27 \AA$ ) of a MP ever solved by SP cryo-EM, those of the transient receptor potential cation channel V1 (TRPV1) (Cao et al., 2013; Liao et al., 2013). To date, the use of NAPols has been reported in only one cryo-EM structure, that of the outer mitochondrial membrane translocase (TOM) core complex (pdb accession code: 5O8O); however, due to indistinguishable 3D maps of the complex in DDM and NAPols, the two datasets have been merged into a single map refined to $6.8 \AA$ (Bausewein et al., 2017) and therefore have not been included among the reports analyzed in this review.
The co-polymerization of styrene and maleic acid yields APol variants known as SMA co-polymers (Figure 5). SMAs form with lipids and MPs the so-called SMALPs. Their interest derives mainly from to their ability to extract MPs from membranes without resorting to detergents (Knowles et al., 2009; Stroud et al., 2018). As of January $1^{\text {st }}, 2021$, only four MP structures had been solved at high resolution using SMAs (Sun et al., 2018; Qiu et al., 2018; Tascón et al., 2020; Yoder and Gouaux, 2020), probably due to a set of limitations that have already been discussed elsewhere (Autzen et al., 2019). For instance, the isolation conditions with SMAs (typically, high ionic strength buffers such as $500 \mathrm{mM} \mathrm{NaCl}$ or L-arginine) and/or the purification conditions (12-24 hours of incubation with affinity resins) tend to be too harsh for fragile MPs of mammalian origin.

CyclAPols, a novel generation of APols that carry cyclic, saturated hydrocarbon chains instead of alkyl ones (Figure 5), have also proven able to directly extract MPs without resorting to detergents while stabilizing target MPs to the same extent as classical APols (Marconnet et al., 2020). With these molecules, the usual protocol of detergent/APol exchange is therefore no longer mandatory. CyclAPols have been recently validated for high-resolution structure determination by SP cryo-EM (Higgins et al., submitted for publication).

Finally, protein-based NDs are nanometric-sized objects of discoidal shape formed by lipid bilayer patches stabilized by two encircling amphipathic helical proteins derived from apolipoprotein A1, called Membrane Scaffold Proteins (MSPs; Figure 6A; for recent reviews see (Denisov and Sligar, 2017; Denisov et al., 2019; Sligar and Denisov, 2020)). The total number of MP structures established in MSP-based NDs at resolutions $\leq 5 \AA$ is 100 . Seven additional structures have been reported using a related system, called Salipro, where another protein, saposin A, replaces MSPs (Figure 6B) (Frauenfeld et al., 2016). Furthermore, three other structures have been obtained with a system called peptidiscs, based on reconstituting the detergent-solubilized MP into short amphipathic bi-helical peptides derived from the apolipoprotein A1 in the absence of additional lipids (Carlson et al., 2018). The main groups of MPs whose structures have been solved after reconstitution in protein-based NDs are channels, ABC transporters, ATPases, Cysloop receptors and members of the TMEM16 family (Figure 6C). At variance with other amphipathic environments, which depend on securing surfactants from commercial sources, protein-based NDs can be produced in the laboratory. MSPs, which can be expressed in E. coli, have been engineered to form NDs of various diameters compatible with the incorporation of MPs of different transmembrane domain sizes. MSP2N2, MSP1E3D1 and MSP1D1 form NDs with diameters comprised between $\sim 10$ and $\sim 17 \mathrm{~nm}$ (Denisov et al., 2004; Grinkova et al., 2010) and are the most frequently used MSPs, with 37, 24 and 22 cryo-EM structures, respectively (Figure 6D). Up to now, the largest transmembrane domains embedded in MSP-based NDs are those of the yeast vacuolar ATPase $\mathrm{V}_{\text {o }}$ proton channel (Roh et al., 2018; Roh et al., 2020) and of the human calcium homeostasis modulator 5 (CALHM5) (Liu et al., 2020), which comprise 48 and 44 transmembrane $\alpha$-helices, respectively. Despite a lower number of transmembrane $\alpha$-helices, the diameter of CALHM5 is wider than that of ATPase $V_{o}$ due to the presence of a large $60-\AA ̊$ diameter pore at the center. In this study, circularized NDs in which the $\mathrm{N}$ and $\mathrm{C}$ termini of MSPs are covalently linked were used, whereas conventional MSP1E3D1 
yielded NDs of sufficient size to accommodate the transmembrane domain ATPase $\mathrm{V}_{\mathrm{o}}$. Circularized NDs were engineered to be more homogeneous and stable than standard NDs (Nasr et al., 2017; Nasr and Wagner, 2018). Circularized MSPs can form NDs of larger diameter ( $50 \mathrm{~nm}$, and up to $80 \mathrm{~nm}$ ) as compared to standard MSPs, but these wider NDs have yet to yield highresolution cryo-EM structures.

Regarding the lipid components, lipid extracts from natural sources (soybean, brain, Escherichia coli, yeast and thylakoids) are found in almost half of the MP structures established in protein-based NDs (46 cases), whereas pure or mixed synthetic phospholipids are found in 44 cases (Figure 6D). The most frequently used NDs are those resulting from a combination of MSP2N2 and natural lipids.

In 2019 and 2020, MSP-based NDs have been the most widely used system in SP cryo-EM (Figure 7B) because the important role of lipid/MP interactions is being paid increasing attention to. This justifies the choice of NDs, which, at the cost of a lengthy optimization process required to obtain highquality samples, allows one to solve MP structures in an artificial lipid bilayer more similar to the native membrane than any of the other surfactants used in SP cryoEM, barring liposomes. In the past, analyses of MPs embedded into liposomes were essentially performed by subtomography cryo-EM, yielding medium- to low-resolution structural data. More recently, imaging liposome-embedded MPs using SP cryo-EM has been developed based on the method of random spherically constrained (RSC) SP reconstruction. This approach relies on fitting and subtracting a model of the membrane contribution to each image and reconstituting the MP particles alone (Wang and Sigworth, 2010; Tonggu and Wang, 2020). It has yielded cryoEM structures of the large conductance voltage- and calciumactivated potassium (BK) channels first at $17 \AA$ (Wang and Sigworth, 2009), and then at $3.5 \AA$ (Tonggu and Wang, 2018). Recently, another method of cryo-EM data processing was developed to determine high-resolution structures of MPs reconstituted into liposomes, as exemplified by the $3.9-\AA$ structure of the multidrug-resistant transporter AcrB (Yao et al., 2020). These approaches have the unique potential of making it possible to examine the structure of MPs under conditions where they experience a gradient of solutes or a transmembrane electric field. One should nevertheless bear in mind that none of these systems, be they liposomes, MSP-based NDs, SMALPs or MP/APol/lipid complexes, provides MPs with an environment identical to that of the native membrane, if only because, in the latter, the two monolayers have different compositions (for a discussion, see Chapter 3 in ref. (Popot, 2018)).

A practice worth mentioning is the addition, to surfactant-solubilized MPs, of cholesteryl hemisuccinate (CHS; Figure 5), a water-soluble cholesterol analog that improves the stability of many purified MPs (Weiss and Grisshammer, 2002; Magnani et al., 2008; Thompson et al., 2011). According to published reports, 207 MPs out of 604 have been solubilized in the presence of CHS and in 90 cases, CHS was kept along with the purification surfactants, which are preferentially maltosidederived detergents and MNGs (Figure $8 \mathrm{~A}$ ). In total, $71 \%$ of the MP structures solved in the presence of CHS, many of which are GPCRs and channels (Figure 8B), have been obtained with
A

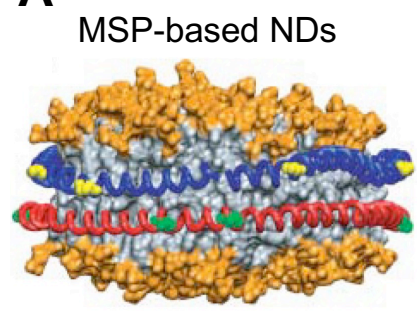

B

Saposin-based NDs

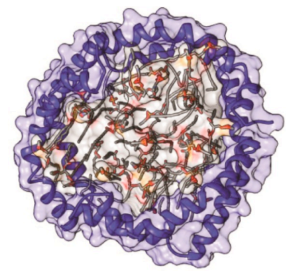

C

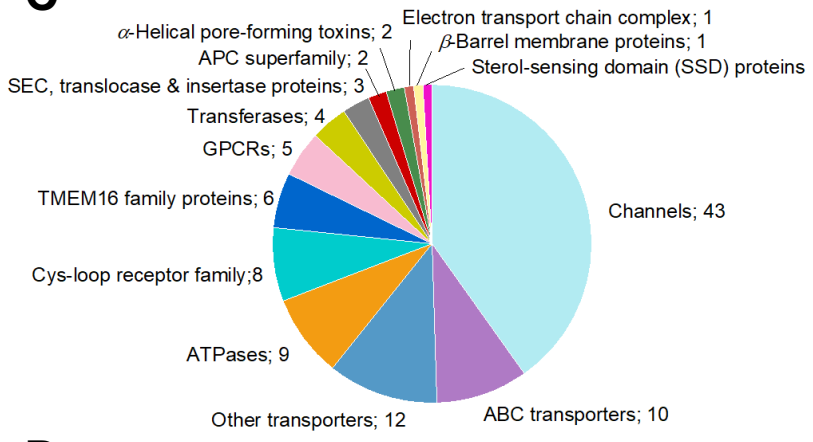

D

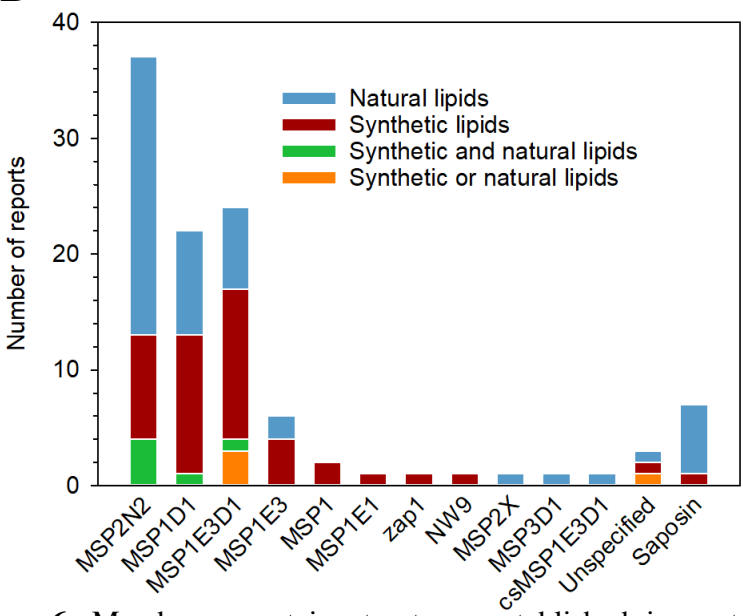

Figure 6. Membrane protein structures established in proteinbased nanodiscs. (A) Molecular model of an MSP-based ND (side view). The two MSPs are shown in red and in blue, the 160 associated lipids in orange and grey. From (Shih et al., 2005). (B) Molecular model of a saposin-based ND (top view). The saposin A dimer is in purple, the 26 associated lipid molecules in reddish brown. From (Li et al., 2016). (C) Family distribution of MPs whose structures have been solved after reconstitution in proteinbased NDs. "Other transporters" comprise cryo-EM structures of three multi-drug efflux transporters, three amino acid secondary transporters, three major facilitator superfamily (MFS) transporters, and three transporters distributed among the three superfamilies of drug/metabolite transporters (DMT), CorA ion transporters and solute carrier (SLC) transporters. (D) Distribution of MSPs and lipids used to reconstitute MPs in protein-based NDs. The MSP called zap1 is derived from Zebra fish apo-lipoprotein A-1; MSP2X was constructed by linking two MSP1E3D1 chains with a twoamino acid linker; csMSP1E3D1 is a circularized version of MSP1E3D1. In three studies, the MSP used has not been clearly mentioned ("unspecified"). When the lipids were a mix of natural and synthetic lipids, they are noted as "natural and synthetic lipids"; when their nature has not been clearly mentioned, as "natural or synthetic lipids". 
A

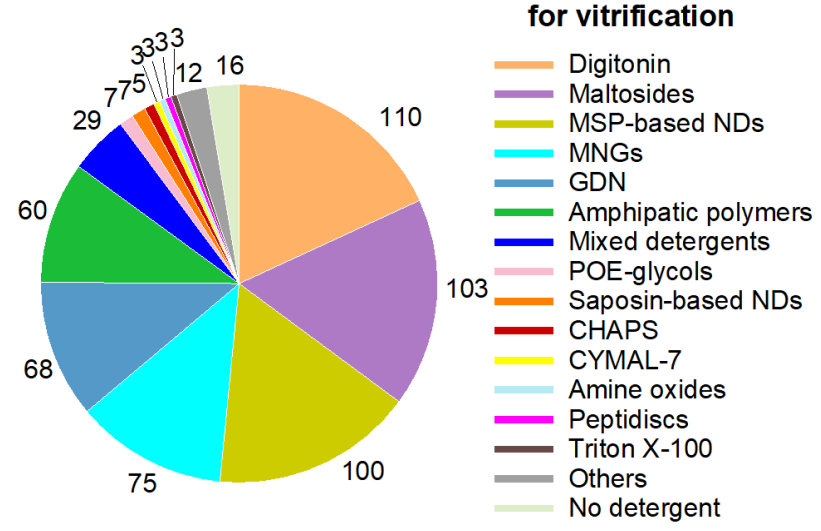

B

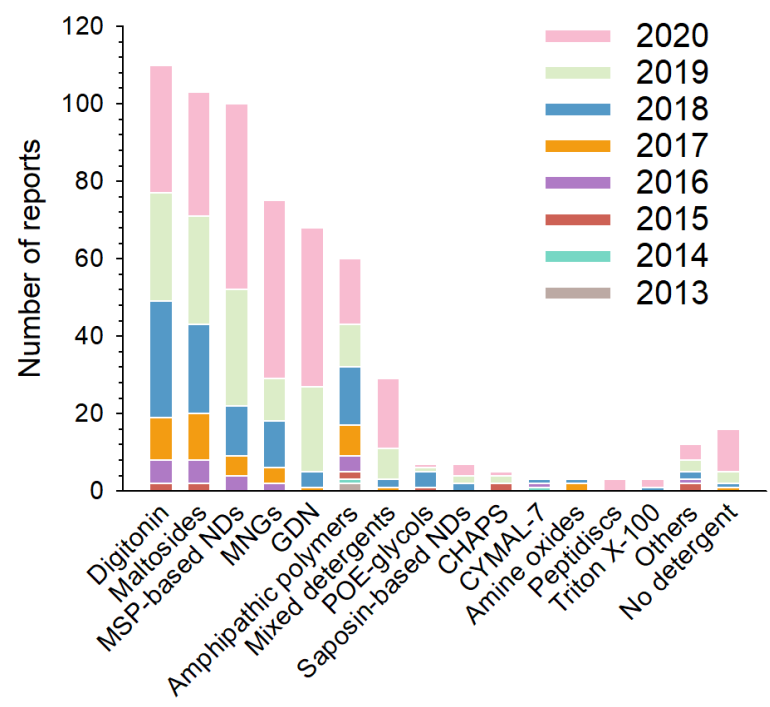

Figure 7. Surfactants used at the vitrification step. (A) Distribution of all surfactants in which MP structures have been solved by SP cryo-EM to a resolution $\leq 5 \AA$ (604 reports overall, taking all duplicates into account). (B) Number of near-atomic resolution MP structures reported each year since 2013 according to the type of surfactant used at the vitrification step. "Others" gather two cryoEM structures obtained in Brij-35 and ten other structures obtained in one of the following surfactants: Tween 20, Igepal CA-630 (NP40), lauryldimethylamine oxide, MNA-C12, PCC-a-M, sodium cholate, Facade-EM (FA-3), octyl glucoside, sodium deoxycholate and liposomes. Sixteen of the cryo-EM structures gathered in Stephen White's database are either MP fragments, toxins or peripheral MPs vitrified in the absence of detergent.

these two detergents. With respect to the total number of MP structures solved in these two surfactant classes, the use of CHS represents $37 \%$ of the cases.

For the sake of exhaustiveness, the present analysis has considered all SP cryo-EM structures solved to resolutions $\leq 5 \AA$. One may argue that a threshold of $4 \AA$ is more appropriate for building high-resolution models (Cheng, 2015). However, this would have reduced the number of experimental conditions to be analyzed from 604 to 487 . We have checked that lowering the threshold from $5 \AA$ to $4 \AA$ has no impact on the general conclusions, i.e. the six most frequently used surf-
A

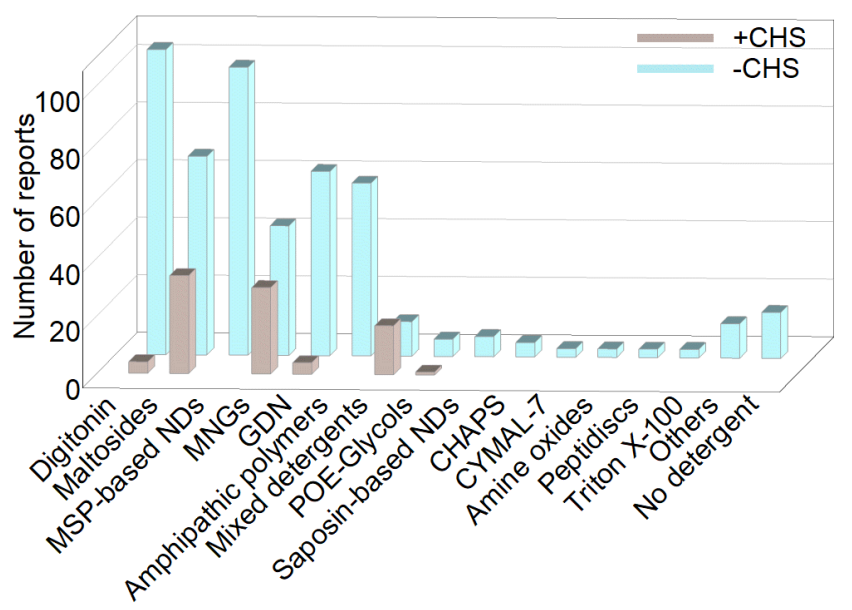

B

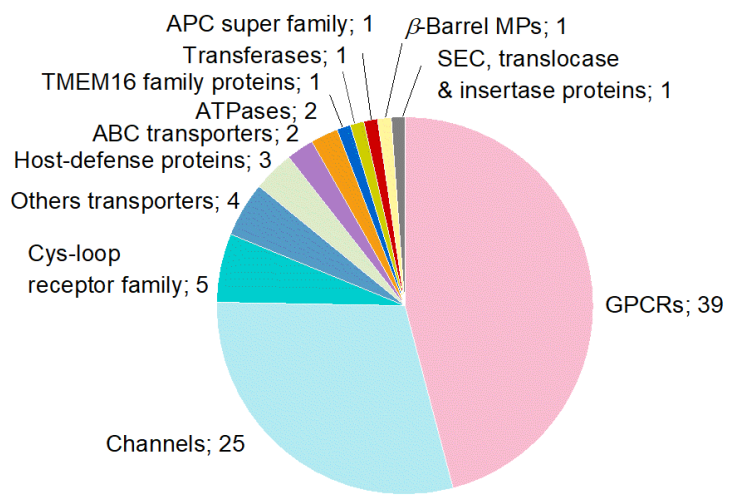

Figure 8. Addition of cholesteryl hemisuccinate (CHS) to MP samples. (A) Purification surfactants used in combination with CHS (B) Distribution of MP structures solved in the presence of CHS among protein classes. "Others" are as described in the legend to Figure 7.

actants remain the same, their ranking changing as follows: MSP-based NDs now come first, with $18 \%$ of the structures, closely followed by maltoside detergents and digitonin, with almost $18 \%$ and $17 \%$, respectively, then MNGs and GDN, each with $12 \%$, and APols with $~ 9 \%$. One clear lesson is that, as of now, no surfactant has emerged as the universal best environment for high-resolution SP cryo-EM.

\section{Surfactant exchange before sample application to the grid}

The surfactant used for protein purification is very often exchanged before the sample is applied onto the grids (Figure 9; for references, see Table S1 in the S.I.). Most often, extraction from the membrane and the first steps of purification are performed using one surfactant (hereafter referred to as the "purification surfactant"), whereas the last steps are used to exchange it for that in which the sample will be vitrified ("vitrification surfactant"). Maltoside detergents are most frequently used for purification ( 44\%), followed by MNGs $(\sim 23 \%)$ and digitonin $(\sim 11 \%)$ (Figure $9 \mathrm{~A})$. However, in $\sim 68 \%$ of cases, MPs purified in maltoside detergents (essentially DDM) were subsequently transferred to a different amphipathic environment, most often MSP-based NDs, APols, digitonin or GDN, before applying the sample to the grids (Figure 9B). In nine cases, the maltoside detergent used for purification was exchan 
A

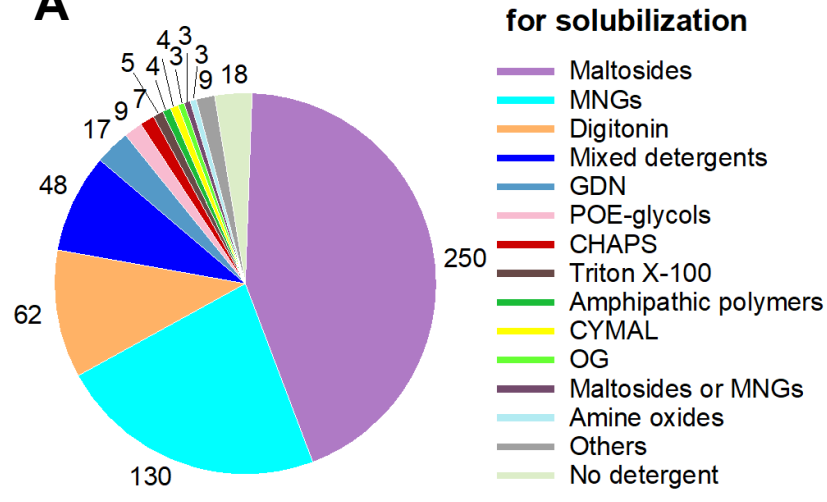

\section{B Surfactants used for solubilization}
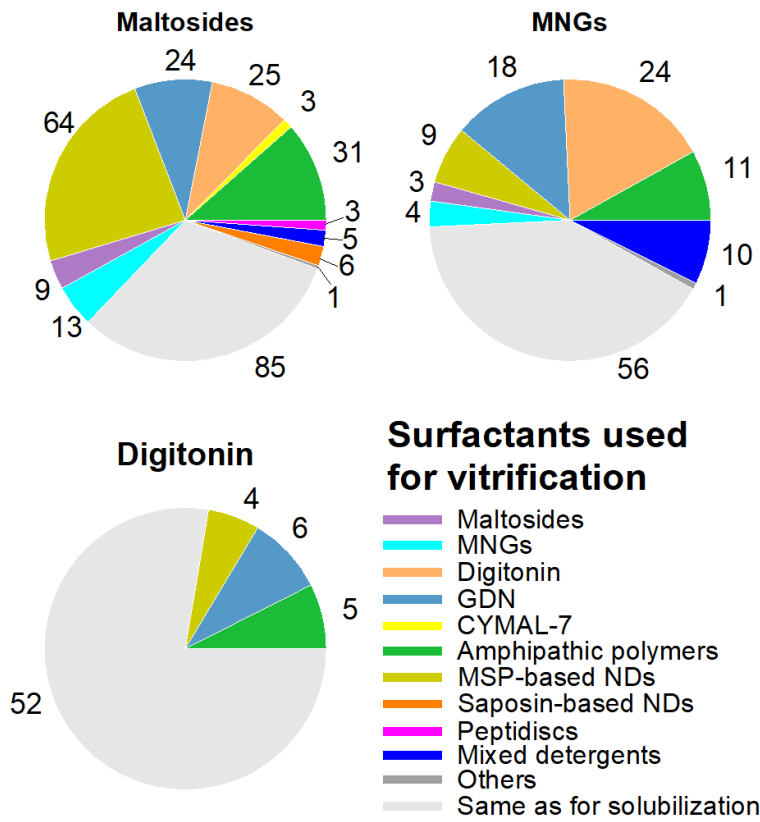

Figure 9. Surfactant exchange between MP purification and sample deposit onto cryo-EM grids. (A) Detergents used for MP solubilization and the initial steps of purification. In three cases (labeled "Maltoside or MNGs"), the detergent used for solubilization has not been clearly specified. (B) Surfactants used for vitrification, depending on which detergent was used for solubilization, namely either maltoside detergents (mainly DDM), MNGs (mainly LMNG), or digitonin. In Panel A, the analysis includes duplicates provided that the surfactants used for solubilization was different (i.e. including duplicates 2 and 3), whereas in panel B all duplicates leading to $\leq 5 \AA$ structures have been included. References to studies using the combinations of surfactants shown in Fig. 9B are given in the S.I. in the legend to Table S1.

ged for another maltoside detergent. Exchange of MNGs is also very common ( $59 \%$ of cases), most often for digitonin, GDN or APols. Digitonin is less often exchanged. Out of 67 structures of MPs purified in digitonin (taking into account duplicates), 52 were obtained without resorting to surfactant exchange (Figure 9B). Figure 10 summarizes, for each of the six types of surfactants most commonly used at the vitrification step, which medium the proteins were initially purified in. Slightly more than half of MPs whose structure was solved in digitonin were purified in other detergents, mainly maltoside-based detergents and

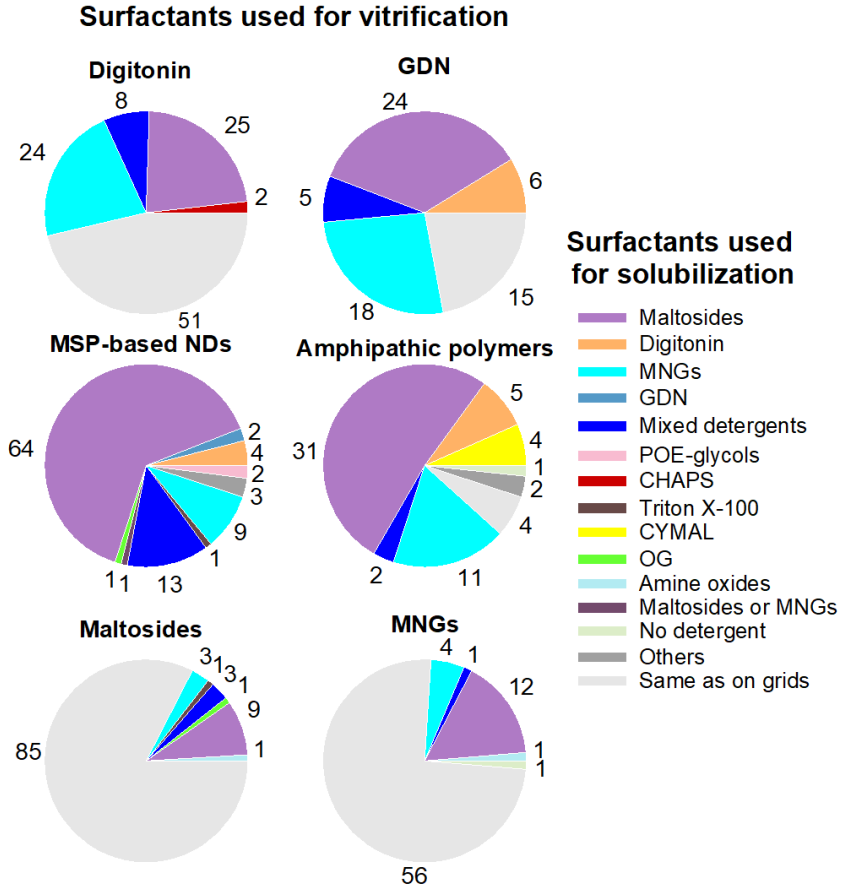

Figure 10. Surfactants used for solubilization and the initial steps of purification, depending on which surfactant was used for vitrification (either digitonin, GDN, MSP-based NDs, APols, maltoside detergents, or MNGs). All duplicates are included. In one case, the detergent used for vitrification has not been clearly specified and could be either maltosides or MNGs.

MNGs. The frequent transfer to digitonin of MPs extracted with another detergent is not unexpected, given that digitonin is both less solubilizing and less destabilizing than most detergents. A large fraction of those MPs whose structure was solved in GDN were initially purified in maltoside detergents or in MNGs (Figure 10).

When MSP-based NDs or APols are used for vitrification, surfactant exchange is most often obligatory, given that neither of these surfactants are effective for direct solubilization. In the case of APols, one can expect that the number of structures solved without surfactant exchange will increase should the use of SMAs and other APols suitable for direct MP extraction, like CyclAPols, develop in the future. Currently, near two thirds and half of the MPs whose structures were established in MSP-based NDs or in APols, respectively, were purified in maltoside detergents (Figure 10).

MNGs are also often chosen as final surfactants. Almost three quarters of the MP structures established in MNGs were obtained without detergent exchange. In $16 \%$ of the cases, the MP was first extracted using a maltoside-based detergent. In four cases, the MNG used for purification was exchanged before vitrification for another MNG.

DDM is, by far, the detergent that is the most often used for MP extraction and purification (Figure 9A). As such, it is, most likely, the first detergent tested in initial imaging attempts. It is therefore noteworthy that DDM is, nevertheless, replaced with another surfactant in more than two thirds $(\sim 68 \%)$ of the studies we examined (Figure 9B). Conversely, DDM and the other maltoside detergents are seldom used to replace the detergent used for purification (Figure 10). There are likely two main reasons for moving or keeping away from DDM for ima- 
ging: $i)$ the desire to transfer the protein to less perturbing and/or more native-like an environment, and ii) the higher quality of images obtained with other surfactants. These two issues, of course, are not independent from each other.

Overall, the analysis summarized in Figures 9 and 10 indicates that it is more the exception than the rule that the surfactant used for extraction and purification be the one kept for preparing cryo-EM specimens, as it is exchanged in $60 \%$ of the cases. Table S1 of the S.I. provides references to those studies in which the protein was initially obtained in one of the three types of surfactants most commonly used for purification, maltosides, MNGs and digitonin, sorted out according to what the medium used for vitrification was.

In any original study of a new MP, optimization of the purification and vitrification conditions is likely to stop once the quality of images appears sufficient for obtaining near-atomic resolution. In subsequent studies, however, when a better structural preservation and/or resolution is desired, or a different conformational state is explored, the search for improved conditions is broadened and may well lead to favoring another surfactant than that used in the first study. Because surfactants that have given good results in the past are tested first, there is initially a bias in their favor, which does not necessarily reflect an actual superiority, and the use of novel molecules tends to lag behind. A notable exception to this pattern is GDN, which, certainly by virtue of its similarity to digitonin and the advantages it presents over it, seems to have been adopted with remarkable rapidity.

\section{Effect of surfactants on image quality}

Many parameters affect the resolution of cryo-EM structures, including the number of particles used for the $3 \mathrm{D}$ reconstruction, grid preparation, imaging conditions, etc. A straightforward relationship between the surfactants used and image quality is therefore difficult to establish. However, a few cryo-EM studies have reported duplicate (or, in two cases, triplicate) structures of the same MP in two (or three) distinct amphipathic environments. One can expect that, in each of these studies, where the starting material is the same, all efforts have been made to optimize image quality and that, as a consequence, differences of resolution from one surfactant to the next can be more likely related to the surfactant itself than to any other factor.

Whereas high-CMC detergents are known to degrade the quality of images due to $i$ ) their tendency to destabilize MPs (cf. Chapter 2 in ref. (Popot, 2018)) and ii) the presence of abundant micelles in the background, which lowers the contrast, resorting to low-CMC detergents tends to improve the resolution. These detergents, such as LMNG, exhibit an extremely slow off-rate, which has been used to develop a gradient-based detergent removal (GraDeR) approach enabling an extensive elimination of free detergent micelles and detergent monomers to further improve image quality (Hauer et al., 2015). Empty NDs and APol excess can also be removed from the samples, before vitrification, by size exclusion chromatography.

Because it is not known beforehand which amphipathic environment will yield the best data, using in parallel two or more vitrification surfactants, which, a few years ago, was an anecdotal practice, is becoming increasingly frequent. Table 1 shows a comparison of the resolutions achieved for a given MP or MP complex, in a given study, in the presence of various amphipathic environments (the best resolution achieved in a given study is noted in red, the surfactant used indicated on the top line, whereas other data obtained in the same study using an alternative surfactant - reported in the left column - are noted in black). It reveals a clear tendency in favor of MSP-based NDs (12 of the best structures), followed by GDN (6), maltosidebased detergents, MNGs and APols ( 5 each). An additional benefit of such comparative approaches is that two structures solved at similar resolution in distinct environments may reveal different conformations, which could provide a glimpse into the conformational landscape of the protein. A case in point is mouse TMEM16A, whose structures in LMNG and NDs show what seems to be two distinct closed conformations, featuring either one or two bound $\mathrm{Ca}^{2+}$ ions per monomer (Dang et al., 2017). There are other such examples in the literature, such as, for instance, the cryo-EM structures of the full-length rabbit TRPV2 channel obtained in APols vs. MSP-based NDs (Zubcevic et al., 2019). This suggests that different amphipathic environments exert different constraints on the transmembrane domain of a given MP, leading to the stabilization of different conformational states. Molecular dynamics data show that APols may slow down MP dynamics (Perlmutter et al., 2014). On the one hand, this probably contributes to stabilizing MPs as compared to conventional detergents (Picard et al., 2006; Pocanschi et al., 2013); on the other, it may favor low-energy conformational states. This can be seen as an advantage to reduce the conformational heterogeneity of samples, like nanobodies and/or Fabs do. Compared to APols, NDs may restrict transmembrane domain conformational states to a lesser extent. Nevertheless, a tight wrapping of MPs by MSPs has been reported (for examples, see (Arkhipova et al., 2020; Roh et al., 2020)), which may potentially give rise to conformational constraints. The presence of lipids in MP/ND or MP/polymer complexes may increase the dynamics of the system, allowing MPs to adopt a range of conformations, which can be relevant to the protein's function.

In other studies, on the contrary, no significant differences were observed, as is the case of the 3.8 - $\AA$ resolution structures of the innexin-6 (INX-6) gap junction proteins in an undocked hemichannel observed in either NDs or MNG (Burendei et al., 2020), or of the 2.9- $\AA$ resolution structures of the human potassium-chloride cotransporter (KCC1) in NDs $v s$. GDN (Liu et al., 2019b). In one case, three cryo-EM structures of the same MP, the autophagy-related 9 (ATG9) protein, were resolved in three different environments, namely MSP-based NDs, APols and LMNG. Whereas no significant differences were observed between NDs and APols, both surfactants leading to 3.4- $\AA$ structures with an r.m.s.d. over all C $\alpha$ atoms of $0.68 \AA$, the use of LMNG resulted in a lesser resolution (Maeda et al., 2020). In four cases, the absence of differences between distinct amphipathic environments led to merging different datasets to build a single cryo-EM structure (whose resolution is noted in green in Table 1).

Over the years, groups that initially used a particular surfactant to study a given MP or MP complex may move to another one. A case in point is that of mitochondrial respiratory supercomplexes, historically solubilized and purified in digitonin. Different types of supercomplexes have been identified, the biggest one being the respirasome, which results from the association of complexes $\mathrm{I}_{1} \mathrm{III}_{2} \mathrm{IV}_{1}$, comprising altogether 80 subunits and featuring 132 transmembrane helices. 


\begin{tabular}{|c|c|c|c|c|c|c|c|}
\hline \multirow{2}{*}{$\begin{array}{l}\text { Surfactants } \\
\text { used for vitri- } \\
\text { fication }\end{array}$} & \multicolumn{7}{|c|}{ Surfactants giving the highest resolution $(\AA)$} \\
\hline & Digitonin & Maltosides & MSP-based NDs & MNGs & Amphipathic polymers & GDN & Others $^{\mathrm{k}}$ \\
\hline Digitonin & $\begin{array}{l}3.2 ; 3.8^{\mathrm{a}}(\mathrm{Tao} \text { and } \\
\text { MacKinnon, 2019) }\end{array}$ & 4 (Sui et al., 2018) & $\begin{array}{l}\text { 3.2; } 3.5 \text { (Feng et al., 2019) } \\
\text { 3; } 3.9 \text { (Bloch et al., 2020) }\end{array}$ & & 4.2; 4.3 (Yin et al., 2019) & $\begin{array}{l}\text { 4.24; } 4.3 \text { (Singh et al., 2018) } \\
3.3 ; 3.5 \text { (Yan et al., 2019) } \\
\text { 2.6; 2.9 (Zhao et al., 2019) }\end{array}$ & \\
\hline Maltosides & 4 (Sui et al., 2018) & $\begin{array}{c}3,3 ; 3.9^{\mathrm{b}} \text { (Gopalasingam et al., } \\
\text { 2019) } \\
3,3 ; 3.9^{\mathrm{c}} \text { (Niu et al., 2020) }\end{array}$ & 3.1; 3.4 (Reddy et al., 2019) & 3.2; 4 (Parey et al., 2019) & $\begin{array}{l}6.8 \text { (Bausewein et al., 2017) } \\
3.1 \text { (Johnson et al., 2020) }\end{array}$ & & $\begin{array}{l}\text { 3.1 (Johnson et } \\
\text { al., 2020) }\end{array}$ \\
\hline $\begin{array}{l}\text { MSP-based } \\
\text { NDs }\end{array}$ & $\begin{array}{l}\text { 3.2; } 3.5 \text { (Alvadia et al., } \\
\text { 2019) }\end{array}$ & $\begin{array}{c}\text { 3.7(3.6); } 3.8(3.6) \mathrm{g} \text { (Kalienkova } \\
\text { et al., 2019) }\end{array}$ & $\begin{array}{c}\text { 3.6; } 3.8^{\mathrm{d}} \text { (Srivastava et al., } \\
\text { 2018) } \\
\begin{array}{c}\text { 3.5; } 3.93 \text { (Kishikawa et al., } \\
2020) \\
3.5 ; 8.25 \text { (Guan et al., 2020) }\end{array}\end{array}$ & $\begin{array}{c}\text { 3.67; } 4.92 \text { (Wang et al., } \\
2020 \mathrm{~b} \text { ) } \\
\text { 3.8; } 3.8^{\text {hi; ( }} \text { (Dang et al., } \\
\text { 2017; Burendei et al., } \\
2020 \text { a) } \\
4.1 ; 6.6 \text { (Jin et al., 2020) }\end{array}$ & $\begin{array}{c}3.7 \text { (Yoo et al., 2018) } \\
\text { 2.9; } 3.8 \text { (Zubcevic et al., } \\
\text { 2019) } \\
\text { 3.4; } 3.4 \text { (Maeda et al., 2020) }\end{array}$ & $\begin{array}{c}\text { 3.96; 7.77 (Walter et al., } \\
\text { 2019) } \\
\text { 2.9; } 2.9 \text { (Liu et al., 2019b) } \\
\text { 3; } 3.39 \text { (Deng et al., 2020b) }\end{array}$ & \\
\hline $\begin{array}{c}\text { Saposin-based } \\
\text { NDs }\end{array}$ & & $\begin{array}{c}\text { 3.8; } 5 \text { (Nguyen et al., 2018) } \\
\text { 3.34; } 4.7 \text { (Gharpure et al., } \\
\text { 2019) }\end{array}$ & & & & & \\
\hline MNGs & & & $\begin{array}{c}\text { 3.1; } 3.5 \text { (Jojoa-Cruz et al., } \\
\text { 2018) } \\
\text { 3.8; 3.8h: (Zhou et al., 2017; } \\
\text { Burendei et al., 2020b) } \\
\text { 3.4; } 4 \text { (Maeda et al., 2020) }\end{array}$ & & $\begin{array}{c}\text { 4.06; } 4.65 \text { (Zhou et al., } \\
2017 \text { ) } \\
\text { 4; 4.1 (Kuhlen et al., 2020) } \\
\text { 3.6; } 3.6 \text { (Vinayagam et al., } \\
\text { 2020) } \\
\text { 3.4; } 4 \text { (Maeda et al., 2020) }\end{array}$ & & $\begin{array}{l}4.1 ; 4.2(\mathrm{Ben}- \\
\text { ton et al., 2018) }\end{array}$ \\
\hline $\begin{array}{l}\text { Amphipathic } \\
\text { polymers }\end{array}$ & & $\begin{array}{c}\text { 6.8 (Bausewein et al., 2017) } \\
\text { 3.4; } 3.5 \text { (Zubcevic et al., 2018) } \\
\text { 3.1 (Johnson et al., 2020) }\end{array}$ & $\begin{array}{c}\text { 3; } 4 \text { (Shen et al., 2016) } \\
3.7 \text { (Yoo et al., 2018) } \\
\text { 3.6; } 4.2 \text { (McGoldrick et al., } \\
\text { 2018) } \\
\text { 3.15; 3.16(Sauer et al., } \\
\text { 2020) } \\
\text { 3.4; } 3.4 \text { (Maeda et al., 2020) }\end{array}$ & $\begin{array}{c}\text { 3.58; } 6.25 \text { (Alam et al., } \\
\text { 2018) } \\
\text { 2.6; } 3.3 \text { (Zhao et al., 2020) } \\
\begin{array}{c}\text { 3.6; } 3.6 \text { (Vinayagam et al., } \\
\text { 2020) }\end{array}\end{array}$ & $\begin{array}{c}3.63 ; 4.2^{\mathrm{e}} \text { (Wang et al., } \\
2019) \\
2.17 ; 3^{\mathrm{f}}(\text { Owji et al., 2020) }\end{array}$ & $\begin{array}{l}2.83 ; 6.04 \text { (Ruan et al., } \\
\text { 2020a) }\end{array}$ & $\begin{array}{l}\begin{array}{l}\text { 3.1 (Johnson et } \\
\text { al., 2020) }\end{array}\end{array}$ \\
\hline GDN & & $\begin{array}{c}\text { 3.06; } 4.1 \text { (Tucker and Park, } \\
\text { 2019) }\end{array}$ & $\begin{array}{c}\text { 4; } 4 \text { (7.9)j (Koehl et al., } \\
\text { 2019) } \\
\text { 3.45; } 3.53 \text { (McGoldrick et } \\
\text { al., 2019) } \\
\text { 2.9; } 2.9 \text { (Liu et al., 2019b) } \\
\text { 3.1; } 3.7 \text { (Gao et al., 2020a) } \\
\text { 3;3.6 (Qian et al., 2020) } \\
\text { 3.4; } 3.6 \text { (Diederichs et al., } \\
\text { 2020) }\end{array}$ & & & & \\
\hline CHAPS & $\begin{array}{c}\text { 3.6; } 4.2 \text { (Gong et al., } \\
2019 \text { ) }\end{array}$ & & & & & & \\
\hline
\end{tabular}


Table 1. A comparison of resolutions achieved for a given MP or MP complex vitrified in various amphipathic environments.

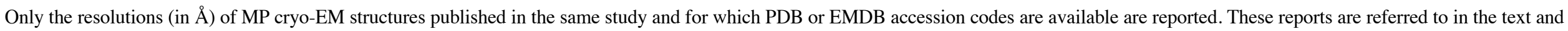

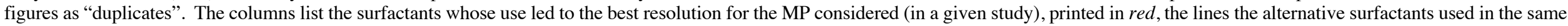

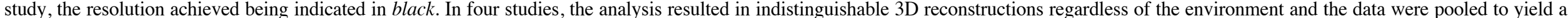

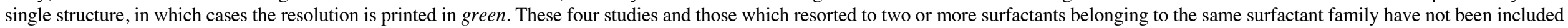
in the total number of best-resolution structures achieved with each surfactant family (last line).

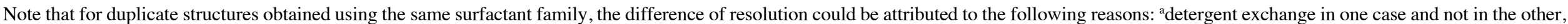

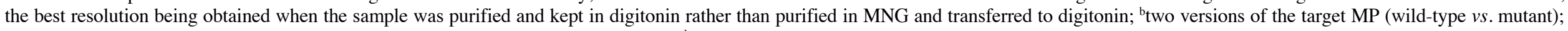

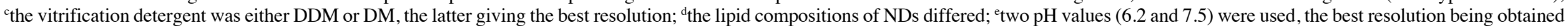
at the highest $\mathrm{pH}$; the vitrification surfactant was either A8-35 or PMAL-C8, the latter giving the best resolution.

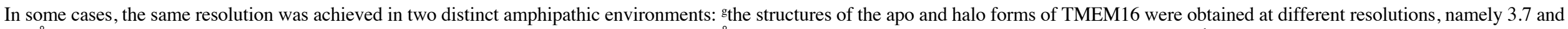

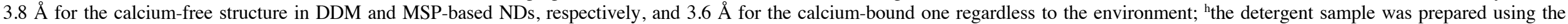

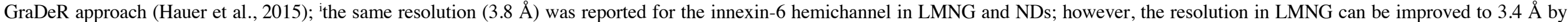

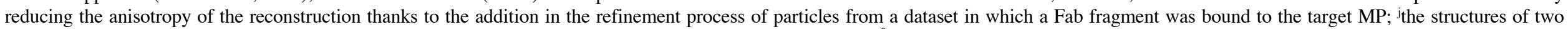

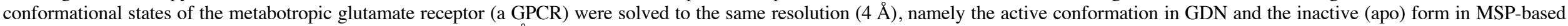

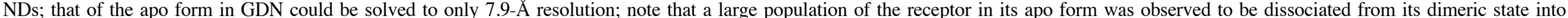

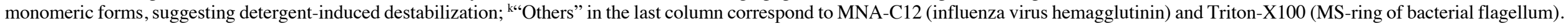


The digitonin/protein ratio used during solubilization considerably affects the types and relative amounts of supercomplexes (Pérez-Pérez et al., 2016), pointing to a dissociating effect. The first $3 \mathrm{D}$ reconstruction ever achieved of a whole mammalian respirasome, which predated the "resolution revolution" in SP cryo-EM, was obtained by stabilizing the supercomplex in APol A8-35 after extracting it with digitonin. Whereas the resolution of the map was limited to $\sim 19 \AA$, it made it possible to position the three respiratory complexes with respect to each other within the supramolecular assembly (Althoff et al., 2011). Five years later, thanks to progress in cryo-EM technology, four structures of respirasomes from three different organisms were obtained at subnanometer resolution and published nearly simultaneously (Letts et al., 2016; Sousa et al., 2016; Gu et al., 2016; Wu et al., 2016). In one study, it was reported that $42 \%$ of the particles had lost complex IV when purified in digitonin, whereas the particles extracted with a DDM analog, PCC-a-M (Hovers et al., 2011), and transferred to A8-35 were homogeneous and stable (Sousa et al., 2016). In another study, where digitonin was used both for purification and vitrification, two 3D reconstructions of the ovine respirasome in "tight" and "loose" forms were obtained at resolutions of $5.8 \AA$ and $6.7 \AA$, respectively (Letts et al., 2016). Over storage, the ratio of the tight to loose respirasomes changed in favor of the loose form, whose population doubled after an overnight incubation at $4{ }^{\circ} \mathrm{C}$ before grid preparations. In the same study, the authors also presented the cryo-EM structure of supercomplex $\mathrm{I}_{1} \mathrm{III}_{2}$ in digitonin at $7.8 \AA$. More recently, the same authors reported that transferring the digitonin-solubilized supercomplex $\mathrm{I}_{1} \mathrm{III}_{2}$ to APol A835 preserved all expected enzymatic activities and significantly improved the surpercomplex stability over time, leading to cryo-EM structures solved, in four distinct states, at resolutions ranging from 4.6 to $3.8 \AA$ (Letts et al., 2019). Nevertheless, replacing digitonin by APol is most likely not the only reason explaining the improvement of resolution, as other parameters such as the number of particles, grid preparation and imaging conditions may have affected the final resolution of the 3D reconstruction. In addition, one should keep in mind that, despite their lesser dissociating character as compared to detergents, too high an excess of APols can also result in breaking up large MP complexes into subfragments (Popot et al., 2011; Sverzhinsky et al., 2014). This process can be limited by $i$ ) fine-tuning the APol concentration following a rather simple method (for a detailed protocol, see (Le Bon et al., 2018)), ii) using less dissociating APols such as NAPols, and iii) adding lipids.

\section{Vitrification}

The usual approach to vitrification is as follows: the carbon film of a cryo-EM grid is rendered hydrophilic by plasma treatment, the sample is deposited on the grid and incubated in a chamber under controlled humidity and temperature, excess liquid is removed (blotted) by touching the surface of the grid with a filter paper, and the resulting thin supported liquid film is flash-frozen by immersion into a cryogen (typically liquid ethane) (Dobro et al., 2010; Sgro and Costa, 2018). Blotting is considered one of the critical steps for achieving reproducible ice quality and thickness (Armstrong et al., 2020). Processes that avoid the hard-to-standardize contact with a filter paper are thus being developed. These include self-blotting grids (nanowire support grids absorbing the excess liquid due to an increased adsorption surface (Razinkov et al., 2016)), removal of excess liquid by applying a pressure gradient ('Preassis' (Zhao et al., 2019b)), microfluidic isolation and controlled deposition of the protein of interest (Schmidli et al., 2019), or automated deposition of minimal sample volumes, either directly ('Spotiton' inkjet dispenser (Arnold et al., 2017); 'Vitrojet' pin-printing (Ravelli et al., 2020)) or through microfluidic-based (Feng et al., 2017) or ultrasound-based (Ashtiani et al., 2018) spraying. To our knowledge, no new structure has so far been solved using any of the latter prototypes, despite promising preliminary results. Commercial vitrification devices based on blotting (sold by FEI, Leica and Gatan) remain overwhelmingly dominant ( $\sim 95 \%$ of the studies). Including home-made devices, more than $97 \%$ of the sample preparation are performed with a paperbased blotting step (the missing 3\% reflecting a lack of information rather than blotting alternatives). This might be attributable to a lack of visibility/availability of newly developed prototypes, or to still ongoing proof-of-concept studies. A point to keep in mind is that, at the blotting stage, most of the surfactant adsorbed at the air/water interface will be removed. The rate of reformation of a surfactant monolayer will depend on the nature and concentration of the surfactant, which may affect such factors as thinning of the film and MP adsorption at the interface.

\section{Can surfactants be used as vitrification helpers?}

The preparation of high-quality cryo-EM grids depends on being able to preserve the target macromolecule in a vitreous thin film, with the particles exhibiting an even distribution and, ideally, adopting random orientations within the ice layer. The key to achieving high resolution is a careful optimization of cryo-specimen preparation (Sgro and Costa, 2018). For MP samples, the presence of surfactant represents a critical factor. Several types of difficulties have been identified, including uneven dispersion of MPs throughout the ice film (aggregation at the edge of the holes in carbon films, particularly if the ice film is too thin, and/or preferential orientations) and lowering of the contrast due to the presence of detergent micelles in the background. The latter problem has encouraged the use of APols, NDs or low-CMC detergents to minimize the presence of free surfactant. MP dispersion within the ice film constitutes the most difficult parameter to control (Drulyte et al., 2018). Commercial cryo-EM grids are metal mesh grids, typically copper, with a support film of amorphous carbon layered over the top, which can be either continuous or perforated. Amorphous carbon support films remain the preferred cryo-EM support material because it is relatively inexpensive. However, it is prone to bending and deformation as a result of exposure to the electron beam (Brilot et al., 2012), entailing afterwards a correction of beam-induced movements. All-gold cryo-EM grids, which have been shown to significantly reduce specimen motion during illumination with the electron beam (Russo and Passmore, 2014), are now more frequently tested. Chemical modification of gold-coated grids with a thiol bearing a PEG group has been developed as a mean to reduce the aggregation of soluble proteins on the support and at the edges of the holes (Meyerson et al., 2014), an approach that has also been shown to improve the distribution and orientations of MPs (Blaza et al., 2018). Another approach is the chemical modification of the MP itself by reacting its surface-exposed lysines with an appropriately functionalized low-molecular-mass PEG (Wu et al., 2019; Wu et al., 2020). Obtaining thicker films can alleviate the orientation problem and it seems that APols can help (Flötenmeyer et al., 2007). An additional risk, which affects both MPs and soluble proteins, is protein adsorption at the air/water interface, which 


\begin{tabular}{|c|c|c|c|c|c|c|c|c|c|c|c|}
\hline $\begin{array}{l}\text { Main Additive } \\
\text { surfactant }\end{array}$ & $\begin{array}{l}\text { Fos-choline-8 } \\
(0.5-3 \mathrm{mM})\end{array}$ & $\begin{array}{l}\text { Octyl-maltoside } \\
(0.01 \%-0.5 \%)\end{array}$ & $\begin{array}{l}\text { Fos-choline } 8 \\
(1.5 \mathrm{mM}) \text { or } \\
\text { octyl maltoside } \\
(0.7 \mathrm{mM})\end{array}$ & $\begin{array}{l}n \text {-Octyl- }-\mathrm{D}- \\
\text { glucopyranoside } \\
(0.05 \% \text { or } 0.1 \%)\end{array}$ & $\begin{array}{c}\text { CHAPS/CHAPSO } \\
(0.05 \%-0.2 \%)\end{array}$ & $\begin{array}{l}\text { Brij-35 } \\
(0.02 \%)\end{array}$ & $\begin{array}{l}\text { Digitonin } \\
(0.1 \%)\end{array}$ & $\begin{array}{c}\text { DDM } \\
(0.06 \mathrm{mM})\end{array}$ & $\begin{array}{l}\text { Fos-choline- } \\
\quad 8\end{array}$ & $\begin{array}{c}\mathrm{A} 8-35 \\
(0.0005 \%)\end{array}$ & $\begin{array}{l}\text { PMAL-C8 } \\
(0.1-0.2 \%)\end{array}$ \\
\hline MSP-based NDs & $\begin{array}{c}\text { (Zubcevic et al., 2019; } \\
\text { Falzone et al., 2019; } \\
\text { Khelashvili et al., 2019; } \\
\text { Wang and Boudker, 2020; } \\
\text { Huang et al., 2020b; Fan et } \\
\text { al., 2020; Yin et al., 2020) }\end{array}$ & $\begin{array}{l}\text { (Gatsogiannis et al., 2016; } \\
\text { Willegems and Efremov, } \\
\text { 2018; Kater et al., 2019; } \\
\text { Reddy et al., 2019; Ruan et } \\
\text { al., 2020b; Qian et al., } \\
\text { 2020) }\end{array}$ & & & (Pleiner et al., 2020) & & & & $\begin{array}{l}\text { (Sun and } \\
\text { Mackinnon, } \\
\text { 2020) }\end{array}$ & $\begin{array}{l}\text { (Koehl et } \\
\text { al., 2019) }\end{array}$ & \\
\hline MNGs & (Wasilko et al., 2020) & (Deme et al., 2020) & $\begin{array}{l}\text { (Lauber et al., } \\
\text { 2018) }\end{array}$ & (Yu et al., 2019) & $\begin{array}{c}\text { (Kampjut and } \\
\text { Sazanov, 2019; Maeda } \\
\text { et al., 2020; Kampjut } \\
\text { and Sazanov, 2020; } \\
\text { Pinke et al., 2020) }\end{array}$ & & & & & & \\
\hline Digitonin & $\begin{array}{c}\text { (Guo and Mackinnon, 2017; } \\
\text { Zhang et al., 2017; Liu et al., } \\
\text { 2017; Johnson and Chen, } \\
\text { 2018; Zhang et al., 2018b; } \\
\text { Liu et al., 2019a; Wang et } \\
\text { al., 2020a) }\end{array}$ & & & & & & & & & & \\
\hline Amphipols & (Wang et al., 2019) & & & & & $\begin{array}{l}\text { (Letts et } \\
\text { al., 2019) }\end{array}$ & $\begin{array}{l}\text { (Maldonado } \\
\text { et al., 2020) }\end{array}$ & $\begin{array}{c}\text { (Owji et al., } \\
2020)\end{array}$ & & & $\begin{array}{c}\text { (Owji et al., } \\
2020)\end{array}$ \\
\hline GDN & $\begin{array}{l}\text { (Tucker and Park, 2019; } \\
\text { Itskanov and Park, 2019) }\end{array}$ & & & $\begin{array}{l}\text { (Koehl et al., 2019; } \\
\text { Kim et al., 2020b) }\end{array}$ & & & & & & & \\
\hline Maltosides & $\begin{array}{l}\text { (Tucker and Park, 2019; Niu } \\
\text { et al., 2020) }\end{array}$ & (Coleman et al., 2020) & & & & & & & & & \\
\hline $\begin{array}{l}\text { Saposin-based } \\
\text { NDs }\end{array}$ & $\begin{array}{l}\text { (Gharpure et al., 2019; Kim } \\
\text { et al., 2020a; Rahman et al., } \\
\text { 2020) }\end{array}$ & & & & & & & & & & \\
\hline POE-Glycols & (Basak et al., 2019) & & & & & & & & & & \\
\hline $\begin{array}{l}n \text {-Octyl- -D- } \\
\text { glucopyranoside }\end{array}$ & & & & (Benton et al., 2020) & & & & & & & \\
\hline No surfactant $\mathrm{t}^{\mathrm{a}}$ & & $\begin{array}{l}\text { (Linsky et al., 2020; Piton } \\
\text { et al., 2020) }\end{array}$ & & (Gao et al., 2020b) & & & & & & & \\
\hline Total & 24 & 10 & 1 & 5 & 5 & 1 & 1 & 1 & 1 & $\mathbf{1}$ & 1 \\
\hline
\end{tabular}

Table 2. Studies in which the addition of secondary surfactants to solubilized MP samples has been carried out before vitrification.

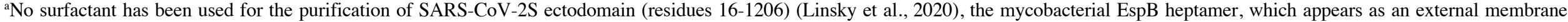
protein (Piton et al., 2020), and the visual G protein-effector complex, a peripherally attached complex to the rod photoreceptor outer segment membranes (Gao et al., 2020b). 
generally results in partial or complete denaturation (Noble et al., 2018). Immobilizing proteins on a graphene-coated surface is a way to prevent this adsorption, as shown with soluble proteins (D'Imprima et al., 2019). Binding of megabodies has also been reported to randomize the particle distribution in ice for MPs that normally exhibit preferential orientations (Uchański et al., 2021).

Surfactant molecules adsorb at the air/water interface, which has two interesting consequences: on the one hand, this reduces the surface tension of the buffer and likely influences the thinning kinetics; on the other, it creates a barrier that limits protein adsorption and denaturation at the interface (Glaeser et al., 2016; Glaeser and Han, 2017). The first effect adds to the complexity of grid preparation because the rate at which the film drains, its thickness at the time of vitrification and, as a result, the even or uneven distribution and orientation of MPs can be difficult to control. It is, however, a factor that can be harnessed to improve particle distribution ( $c f$. (Flötenmeyer et al., 2007)).

It has been reported that addition of small amounts of surfactants to a sample of soluble proteins can improve particle distribution and/or orientation within the ice film, which facilitates collecting the various views required for 3D reconstruction. This improvement has been observed for instance with detergents like CHAPSO (Chen et al., 2019) as well as with APol A8-35 (Chowdhury et al., 2015; Zhang et al., 2018a). Table 2 lists the cases where a secondary surfactant has been added to solubilized MP samples in order to improve the quality of the samples. NDs and MNGs are the two systems in which addition of extra surfactants has been most often resorted to (Table 2).

Fluorinated surfactants have proven particularly useful for this task because $i$ ) they mix poorly with hydrogenated alkyl chains of detergent molecules and ii) they are strongly attracted to the air/water interface, where they oppose the adsorption of hydrogenated molecules ( $c f$. Chapter 3 in ref. (Popot, 2018)). Fluorinated Fos-choline 8, with a CMC of $2.5 \mathrm{mM}$, is most frequently used, followed by fluorinated octylmaltoside $(\mathrm{CMC}=0.7 \mathrm{mM})$. MP cryo-EM structures have also been obtained using as additives hydrogenated detergents, such as Foscholine 8, DDM, digitonin, CHAPS/CHAPSO, Brij-35 or octylglucoside (Table 2). An interesting observation is that A8-35 can also facilitate sample vitrification for ND-trapped MPs (Koehl et al., 2019). As with small surfactants, the addition of A8-35 seems to oppose the adsorption of MP/ND complexes at the air/water interface, most likely due to its forming an interfacial film (cf. (Giusti et al., 2012)).

Preferential orientation has been reported in the case of the ryanodine receptor RyR1 trapped in A8-35 (Baker et al., 2015). Random orientation of the particles was achieved following addition to the sample of a low concentration of octylglucoside (one tenth of the CMC). The mechanism underlying this effect is not clear (for a discussion, see Chapter 12 in ref. (Popot, 2018)). Combining two or more surfactants can thus have favorable effects, although it complicates optimizing grid preparation.

\section{Using functionalized APols for immobilizing MP complexes or labelling transmembrane domains}

One of the advantages of APols derives from the fact that grafting a small percentage of a tag or label onto the polymer does not affect its solution properties, while functionalizing it for specific purposes. Thereby, transferring a MP from detergents to a functionalized APol results in functionalizing the MP of interest without the need for any chemical nor genetic modification (Della Pia et al., 2014a). This can be achieved either by exchanging detergents for labelled APols (Le Bon et al., 2018) or, given that APols are miscible (Zoonens et al., 2007; Della Pia et al., 2014b), by adding a functionalized APol to a MP directly extracted using the newly developed CyclAPols (Marconnet et al., 2020). Many applications of such a mild labeling can be contemplated. On the one hand, chemically functionalized carbon films carrying biotin, nickel-charged nitrilotriacetic acid ( $\left.\mathrm{Ni}^{2+}-\mathrm{NTA}\right)$, DNA, and so on have been described (Llaguno et al., 2014). Functionalized APols carrying biotin moieties (Charvolin et al., 2009), hexahistidine (His ${ }_{6}$ )-tags (Giusti et al., 2015), or a single strand of DNA (Le Bon et al., 2014) could be used to immobilize MPs on the corresponding films, so as to provide an even distribution and prevent protein contact with the air/water interface. In addition, functionalized APols can be used to label the transmembrane domain of some challenging MP complexes for which only medium- to low-resolution structures are currently available. The principle of this approach has been validated using negative-stain EM (Perry et al., 2019). It relies on trapping the target MP with an APol carrying biotin moieties (BAPol) (Charvolin et al., 2009) and localizing the BAPol-coated transmembrane regions using monovalent streptavidin. This labelling strategy could presumably help in the initial steps of a cryo-EM study, even though it should be kept in mind that streptavidin monomers, while bound to the surface of the APol layer, will not occupy identical positions from one particle to the next. This approach could be extended to other functionalized APols. For instance, APols carrying His $_{6}$-tags (Giusti et al., 2015) can bind $\mathrm{Ni}^{2+}$-functionalized gold nanoparticles or quantum dots, whereas those carrying an oligonucleotide (Le Bon et al., 2014) could be used to create or bind to origami motifs (Martin et al., 2016).

\section{Conclusion}

The present analysis provides an overview of how surfactants are being used in the field of SP cryo-EM MP studies. One remarkable observation is that, even when a mild detergent such as DDM, LMNG, digitonin or GDN is used for MP extraction and purification, microscopists often find it advantageous to exchange it for another surfactant such as a milder detergent, NDs or APols in order to improve the quality of the reconstructions and/or to catch distinct conformational states. One can expect that, in the future, developing still better surfactants will be one of the major avenues to improving cryo-EM data. Two major directions will likely be explored in parallel: $i$ ) improving surfactants that can extract MPs directly while also providing excellent images, so that no surfactant exchange would be necessary, and ii) improving the final surfactant used to maintain MPs in solution during grid preparation, irrespective of whether it is also used for the initial solubilization and purification steps. Further progress will likely also depend on a better control of the factors that govern the thickness of the ice film and the distribution and orientation of $\mathrm{MP} /$ surfactant complexes within it. Here as well, a better understanding of the behavior of surfactants and liquid films at the blotting step will probably prove critical. Finally, the use of functionalized surfactants offers intriguing perspectives. 


\section{Supporting Information}

References to studies resorting to the most commonly used surfactants and combinations thereof are given in Table S1 available in the Supplementary Information.

\section{ACKNOWLEDGMENT}

We would like to thank Daniel Picot for interesting discussions on the 3D reconstruction of structural models solved either by X-ray crystallography or by SP cryo-EM and Mark E. Dumont, Richard Henderson, Pierre D. McCrea and the referees of $Q R B$ for very useful comments on earlier versions of the review. Financial support came from the Centre National de la Recherche Scientifique (CNRS), including specific "80PRIME" grant, and the Université de Paris (Université Paris-7). Additional funding came from the "Initiative d'Excellence" program from the French State (Grant "DYNAMO”, ANR-11-LABX-0011-01).

\section{REFERENCES}

Abeyrathne PD, Arheit M, Kebbel F, Castano-Diez D, Goldie KN, Chami M, Stahlberg H, Renault L and Kühlbrandt W (2012) Analysis of 2-D Crystals of Membrane Proteins by Electron Microscopy. Comprehensive Biophysics, 1, 277-310.

Alam A, Küng R, Kowal J, McLeod RA, Tremp N, Broude EV, Roninson IB, Stahlberg H and Locher KP (2018) Structure of a zosuquidar and UIC2-bound human-mouse chimeric ABCB1. Proceedings of the National Academy of Sciences 115, e1973-1982.

Alnabati E and Kihara D (2019) Advances in Structure Modeling Methods for Cryo-Electron Microscopy Maps. Molecules 25, 82.

Althoff T, Mills DJ, Popot J-L and Kühlbrandt W (2011) Arrangement of electron transport chain components in bovine mitochondrial supercomplex $\mathrm{I}_{1} \mathrm{III}_{2} \mathrm{IV}_{1}$. The EMBO journal 30, 4652-4664.

Alvadia C, Lim NK, Clerico Mosina V, Oostergetel GT, Dutzler R and Paulino C (2019) Cryo-EM structures and functional characterization of the murine lipid scramblase TMEM16F. eLife 8, e44365.

Andréll J and Tate CG (2013) Overexpression of membrane proteins in mammalian cells for structural studies. Molecular Membrane Biology 30, 52-63.

Arkhipova V, Guskov A and Slotboom DJ (2020) Structural ensemble of a glutamate transporter homologue in lipid nanodisc environment. Nature Communications 11, 1-9.

Armstrong M, Han B-G, Gomez S, Turner J, Fletcher DA and Glaeser RM (2020) Microscale Fluid Behavior during Cryo-EM Sample Blotting. Biophysical Journal 118, 708-719.

Arnold SA, Albiez S, Bieri A, Syntychaki A, Adaixo R, McLeod RA, Goldie KN, Stahlberg H and Braun T (2017) Blotting-free and lossless cryo-electron microscopy grid preparation from nanoliter-sized protein samples and single-cell extracts. Journal of Structural Biology 197, 220-226.

Ashtiani D, Venugopal H, Belousoff M, Spicer B, Mak J, Neild A and de Marco A (2018) Delivery of femtolitre droplets using surface acoustic wave based atomisation for cryo-EM grid preparation. Journal of Structural Biology 203, 94-101.
Autzen HE, Julius D and Cheng Y (2019) Membrane mimetic systems in CryoEM: keeping membrane proteins in their native environment. Current Opinion in Structural Biology 58, 259-268.

Baker MR, Fan G and Serysheva II (2015) Single-Particle Cryo-EM of the Ryanodine Receptor Channel in an Aqueous Environment. European Journal of Translational Myology 25, 4803.

Basak S, Gicheru Y, Kapoor A, Mayer ML, Filizola M and Chakrapani S (2019) Molecular mechanism of setron-mediated inhibition of fulllength 5-HT3A receptor. Nature Communications 10, 3225.

Bausewein T, Mills DJ, Langer JD, Nitschke B, Nussberger S and Kühlbrandt W (2017) Cryo-EM Structure of the TOM Core Complex from Neurospora crassa. Cell 170, 693-700.e7.

Bazzacco P, Billon-Denis E, Sharma KS, Catoire LJ, Mary S, Le Bon C, Point E, Banères J-L, Durand G, Zito F, Pucci B and Popot J-L (2012) Nonionic homopolymeric amphipols: application to membrane protein folding, cell-free synthesis, and solution nuclear magnetic resonance. Biochemistry 51, 1416-1430.

Benton DJ, Gamblin SJ, Rosenthal PB and Skehel JJ (2020) Structural transitions in influenza haemagglutinin at membrane fusion $\mathrm{pH}$. $\mathrm{Na}$ ture 583, 150-153.

Benton DJ, Nans A, Calder LJ, Turner J, Neu U, Lin YP, Ketelaars E, Kallewaard NL, Corti D, Lanzavecchia A, Gamblin SJ, Rosenthal PB and Skehel JJ (2018) Influenza hemagglutinin membrane anchor. Proceedings of the National Academy of Sciences of the United States of America 115, 10112-10117.

Bhairi SM and Mohan C (2007) Detergents. A guide to the properties and uses of detergents in biology and biochemistry (Calbiochem booklet), Darmstadt: EMD Biosciences, an affiliate of Merck KGaA.

Bill RM, Henderson PJF, Iwata S, Kunji ERS, Michel H, Neutze R, Newstead S, Poolman B, Tate CG and Vogel H (2011) Overcoming barriers to membrane protein structure determination. Nature Biotechnology 29, 335-340.

Blaza JN, Vinothkumar KR and Hirst J (2018) Structure of the Deactive State of Mammalian Respiratory Complex I. Structure 26, 312319.e3.

Bloch JS, Pesciullesi G, Boilevin J, Nosol K, Irobalieva RN, Darbre T, Aebi M, Kossiakoff AA, Reymond J-L and Locher KP (2020) Structure and mechanism of the ER-based glucosyltransferase ALG6. Nature 579, 443-447.

Brilot AF, Chen JZ, Cheng A, Pan J, Harrison SC, Potter CS, Carragher B, Henderson R and Grigorieff N (2012) Beam-induced motion of vitrified specimen on holey carbon film. Journal of Structural Biology 177, 630-637.

Burendei B, Shinozaki R, Watanabe M, Terada T, Tani K, Fujiyoshi Y and Oshima A (2020) Cryo-EM structures of undocked innexin-6 hemichannels in phospholipids. Science Advances 6, eaax3157.

Cao E, Liao M, Cheng Y and Julius D (2013) TRPV1 structures in distinct conformations reveal activation mechanisms. Nature 504, 113118.

Carlson ML, Young JW, Zhao Z, Fabre L, Jun D, Li J, Li J, Dhupar HS, Wason I, Mills AT, Beatty JT, Klassen JS, Rouiller I and Duong F (2018) The Peptidisc, a simple method for stabilizing membrane proteins in detergent-free solution V. Dötsch \& R. Aldrich, eds. eLife 7, e34085. 
Chae PS, Rasmussen SGF, Rana RR, Gotfryd K, Chandra R, Goren MA, Kruse AC, Nurva S, Loland CJ, Pierre Y, Drew D, Popot J-L, Picot D, Fox BG, Guan L, Gether U, Byrne B, Kobilka B and Gellman SH (2010) Maltose-neopentyl glycol (MNG) amphiphiles for solubilization, stabilization and crystallization of membrane proteins. Nature Methods 7, 1003-1008.

Chae PS, Rasmussen SGF, Rana RR, Gotfryd K, Kruse AC, Manglik A, Cho KH, Nurva S, Gether U, Guan L, Loland CJ, Byrne B, Kobilka BK and Gellman SH (2012) A new class of amphiphiles bearing rigid hydrophobic groups for solubilization and stabilization of membrane proteins. Chemistry (Weinheim an Der Bergstrasse, Germany) 18, 9485-9490.

Charvolin D, Perez J-B, Rouvière F, Giusti F, Bazzacco P, Abdine A, Rappaport F, Martinez KL and Popot J-L (2009) The use of amphipols as universal molecular adapters to immobilize membrane proteins onto solid supports. Proceedings of the National Academy of Sciences of the United States of America 106, 405-410.

Charvolin D, Picard M, Huang L-S, Berry EA and Popot J-L (2014) Solution behavior and crystallization of cytochrome $b_{1}$ in the presence of amphipols. The Journal of Membrane Biology 247, 981-996.

Chen J, Noble AJ, Kang JY and Darst SA (2019) Eliminating effects of particle adsorption to the air/water interface in single-particle cryo-electron microscopy: Bacterial RNA polymerase and CHAPSO. Journal of Structural Biology X 1, 100005.

Cheng Y (2015) Single-particle cryo-EM at crystallographic resolution. Cell 161, 450-457.

Cheng Y (2018) Single-particle cryo-EM-How did it get here and where will it go. Science 361, 876-880.

Chipot C, Dehez F, Schnell JR, Zitzmann N, Pebay-Peyroula E, Catoire LJ, Miroux B, Kunji ERS, Veglia G, Cross TA and Schanda P (2018) Perturbations of Native Membrane Protein Structure in Alkyl Phosphocholine Detergents: A Critical Assessment of NMR and Biophysical Studies. Chemical Reviews 118, 3559-3607.

Chowdhury S, Ketcham SA, Schroer TA and Lander GC (2015) Structural organization of the dynein-dynactin complex bound to microtubules. Nature Structural \& Molecular Biology 22, 345-347.

Choy BC, Cater RJ, Mancia F and Pryor EE (2021) A 10-year metaanalysis of membrane protein structural biology: Detergents, membrane mimetics, and structure determination techniques. Biochimica et Biophysica Acta (BBA) - Biomembranes 1863, 183533.

Coleman JA, Navratna V, Antermite D, Yang D, Bull JA and Gouaux E (2020) Chemical and structural investigation of the paroxetine-human serotonin transporter complex. eLife $\mathbf{9}$, e56427.

Contreras-Gómez A, Sánchez-Mirón A, García-Camacho F, MolinaGrima E and Chisti Y (2014) Protein production using the baculovirus-insect cell expression system. Biotechnology Progress 30, 1-18.

Cooper RS, Georgieva ER, Borbat PP, Freed JH and Heldwein EE (2018) Structural basis for membrane anchoring and fusion regulation of the herpes simplex virus fusogen gB. Nature Structural \& Molecular Biology 25, 416-424.

Cooper RS and Heldwein EE (2020) Expression, Purification, and Crystallization of Full-Length HSV-1 gB for Structure Determination. Methods in Molecular Biology (Clifton, N.J.) 2060, 395-407.

Cross TA, Sharma M, Yi M and Zhou H-X (2011) Influence of solubilizing environments on membrane protein structures. Trends in Biochemical Sciences 36, 117-125.
Dang S, Feng S, Tien J, Peters CJ, Bulkley D, Lolicato M, Zhao J, Zuberbühler K, Ye W, Qi L, Chen T, Craik CS, Jan YN, Minor DL, Cheng Y and Jan LY (2017) Cryo-EM structures of the TMEM16A calcium-activated chloride channel. Nature 552, 426-429.

De Zorzi R, Mi W, Liao M and Walz T (2016) Single-particle electron microscopy in the study of membrane protein structure. Microscopy (Oxford, England) 65, 81-96.

Deme JC, Johnson S, Vickery O, Aron A, Monkhouse H, Griffiths T, James RH, Berks BC, Coulton JW, Stansfeld PJ and Lea SM (2020) Structures of the stator complex that drives rotation of the bacterial flagellum. Nature Microbiology 5, 1553-1564.

Deisenhofer J, Epp O, Miki K, Huber R and Michel H (1985) Structure of the protein subunits in the photosynthetic reaction centre of Rhodopseudomonas viridis at $3 \AA$ resolution. Nature 318, 618-624.

Della Pia EA, Hansen RW, Zoonens M and Martinez KL (2014a) Functionalized amphipols: a versatile toolbox suitable for applications of membrane proteins in synthetic biology. The Journal of Membrane Biology 247, 815-826.

Della Pia EA, Holm JV, Lloret N, Le Bon C, Popot J-L, Zoonens M, Nygård J and Martinez KL (2014b) A step closer to membrane protein multiplexed nanoarrays using biotin-doped polypyrrole. ACS nano 8, 1844-1853.

Deng Z, Maksaev G, Schlegel AM, Zhang J, Rau M, Fitzpatrick JAJ, Haswell ES and Yuan P (2020) Structural mechanism for gating of a eukaryotic mechanosensitive channel of small conductance. Nature Communications 11, 3690.

Denisov IG, Grinkova YV, Lazarides AA and Sligar SG (2004) Directed self-assembly of monodisperse phospholipid bilayer nanodiscs with controlled size. Journal of the American Chemical Society 126, 3477-87.

Denisov IG, Schuler MA and Sligar SG (2019) Nanodiscs as a New Tool to Examine Lipid-Protein Interactions. Methods in Molecular Biology (Clifton, N.J.) 2003, 645-671.

Denisov IG and Sligar SG (2017) Nanodiscs in Membrane Biochemistry and Biophysics. Chemical Reviews 117, 4669-4713.

Diederichs KA, Ni X, Rollauer SE, Botos I, Tan X, King MS, Kunji ERS, Jiang J and Buchanan SK (2020) Structural insight into mitochondrial $\beta$-barrel outer membrane protein biogenesis. Nature Communications 11, 3290 .

Dilworth MV, Piel MS, Bettaney KE, Ma P, Luo J, Sharples D, Poyner DR, Gross SR, Moncoq K, Henderson PJF, Miroux B and Bill RM (2018) Microbial expression systems for membrane proteins. Methods (San Diego, Calif.) 147, 3-39.

D'Imprima E, Floris D, Joppe M, Sánchez R, Grininger M and Kühlbrandt W (2019) Protein denaturation at the air-water interface and how to prevent it. eLife $\mathbf{8}$, e42747.

Dobro MJ, Melanson LA, Jensen GJ and McDowall AW (2010) Plunge freezing for electron cryomicroscopy. Methods in Enzymology 481, 63-82.

Draper-Joyce CJ, Khoshouei M, Thal DM, Liang Y-L, Nguyen ATN, Furness SGB, Venugopal H, Baltos J-A, Plitzko JM, Danev R, Baumeister W, May LT, Wootten D, Sexton PM, Glukhova A and Christopoulos A (2018) Structure of the adenosine-bound human adenosine A 1 receptor-G i complex. Nature 558, 559-563. 
Drulyte I, Johnson RM, Hesketh EL, Hurdiss DL, Scarff CA, Porav SA, Ranson NA, Muench SP and Thompson RF (2018) Approaches to altering particle distributions in cryo-electron microscopy sample preparation. Acta Crystallographica. Section D, Structural Biology 74, 560-571.

Falzone ME, Rheinberger J, Lee B-C, Peyear T, Sasset L, Raczkowski AM, Eng ET, Di Lorenzo A, Andersen OS, Nimigean CM and Accardi A (2019) Structural basis of $\mathrm{Ca}^{2+-}$-dependent activation and lipid transport by a TMEM16 scramblase. eLife 8, e43229.

Fan C, Sukomon N, Flood E, Rheinberger J, Allen TW and Nimigean CM (2020) Ball-and-chain inactivation in a calcium-gated potassium channel. Nature 580, 288-293.

Feng S, Dang S, Han TW, Ye W, Jin P, Cheng T, Li J, Jan YN, Jan LY and Cheng Y (2019) Cryo-EM Studies of TMEM16F Calcium-Activated Ion Channel Suggest Features Important for Lipid Scrambling. Cell Reports 28, 567-579.e4.

Feng X, Fu Z, Kaledhonkar S, Jia Y, Shah B, Jin A, Liu Z, Sun M, Chen B, Grassucci RA, Ren Y, Jiang H, Frank J and Lin Q (2017) A Fast and Effective Microfluidic Spraying-Plunging Method for HighResolution Single-Particle Cryo-EM. Structure 25, 663-670.e3.

Flores JA, Haddad BG, Dolan KA, Myers JB, Yoshioka CC, Copperman J, Zuckerman DM and Reichow SL (2020) Connexin-46/50 in a dynamic lipid environment resolved by CryoEM at $1.9 \AA$. Nature Communications 11, 4331.

Flötenmeyer M, Weiss H, Tribet C, Popot J-L and Leonard K (2007) The use of amphipathic polymers for cryo-electron microscopy of NADH:ubiquinone oxidoreductase (Complex I). Journal of Microscopy 227, 229-235.

Frauenfeld J, Gumbart J, Sluis EO van der, Funes S, Gartmann M, Beatrix B, Mielke T, Berninghausen O, Becker T, Schulten K and Beckmann R (2011) Cryo-EM structure of the ribosome-SecYE complex in the membrane environment. Nature Structural \& Molecular Biology 18, 614-621.

Frauenfeld J, Löving R, Armache J-P, Sonnen AF-P, Guettou F, Moberg P, Zhu L, Jegerschöld C, Flayhan A, Briggs JAG, Garoff H, Löw C, Cheng Y and Nordlund P (2016) A saposin-lipoprotein nanoparticle system for membrane proteins. Nature Methods 13, 345351.

Fukunaga K, Szabo L, Fales HM and Pitha J (1988) 2-Hydroxypropyldigitonin: synthesis and properties of preparations differing in degree of substitution. Journal of Pharmaceutical Sciences 77, 640642.

Gao S, Valinsky WC, On NC, Houlihan PR, Qu Q, Liu L, Pan X, Clapham DE and Yan N (2020a) Employing NaChBac for cryo-EM analysis of toxin action on voltage-gated $\mathrm{Na}^{+}$channels in nanodisc. Proceedings of the National Academy of Sciences of the United States of America 117, 14187-14193.

Gao Y, Eskici G, Ramachandran S, Poitevin F, Seven AB, Panova O, Skiniotis G and Cerione RA (2020b) Structure of the Visual Signaling Complex between Transducin and Phosphodiesterase 6. Molecular Cell 80, 237-245.e4.

Gao Y, Hu H, Ramachandran S, Erickson JW, Cerione RA and Skiniotis G (2019) Structures of the Rhodopsin-Transducin Complex: Insights into G-Protein Activation. Molecular Cell 75, 781790.e3.
Garavito RM and Ferguson-Miller S (2001) Detergents as tools in membrane biochemistry. The Journal of Biological Chemistry 276 , 32403-32406.

Gatsogiannis C, Merino F, Prumbaum D, Roderer D, Leidreiter F, Meusch D and Raunser S (2016) Membrane insertion of a Tc toxin in near-atomic detail. Nature Structural \& Molecular Biology 23 884-890.

Gharpure A, Teng J, Zhuang Y, Noviello CM, Walsh RM, Cabuco R, Howard RJ, Zaveri NT, Lindahl E and Hibbs RE (2019) Agonist Selectivity and Ion Permeation in the $\alpha 3 \beta 4$ Ganglionic Nicotinic Receptor. Neuron 104, 501-511.e6.

Giusti F, Kessler P, Hansen RW, Della Pia EA, Le Bon C, Mourier G, Popot J-L, Martinez KL and Zoonens M (2015) Synthesis of a Polyhistidine-bearing Amphipol and its Use for Immobilizing Membrane Proteins. Biomacromolecules 16, 3751-3761.

Giusti F, Popot J-L and Tribet C (2012) Well-defined critical association concentration and rapid adsorption at the air/water interface of a short amphiphilic polymer, amphipol A8-35: a study by Förster resonance energy transfer and dynamic surface tension measurements. Langmuir: the ACS journal of surfaces and colloids 28, 10372 10380.

Glaeser RM and Han B-G (2017) Opinion: hazards faced by macromolecules when confined to thin aqueous films. Biophysics Reports 3, 1-7.

Glaeser RM, Han B-G, Csencsits R, Killilea A, Pulk A and Cate JHD (2016) Factors that Influence the Formation and Stability of Thin, Cryo-EM Specimens. Biophysical Journal 110, 749-755.

Glavier M, Puvanendran D, Salvador D, Decossas M, Phan G, Garnier C, Frezza E, Cece Q, Schoehn G, Picard M, Taveau J-C, Daury L, Broutin I and Lambert O (2020) Antibiotic export by MexB multidrug efflux transporter is allosterically controlled by a MexA-OprM chaperone-like complex. Nature Communications 11, 4948.

Gong D, Chi X, Wei J, Zhou G, Huang G, Zhang L, Wang R, Lei J, Chen SRW and Yan N (2019) Modulation of cardiac ryanodine receptor 2 by calmodulin. Nature $\mathbf{5 7 2}, 347-351$.

Gopalasingam CC, Johnson RM, Chiduza GN, Tosha T, Yamamoto M, Shiro Y, Antonyuk SV, Muench SP and Hasnain SS (2019) Dimeric structures of quinol-dependent nitric oxide reductases (qNORs) revealed by cryo-electron microscopy. Science Advances 5, eaax 1803.

Grinkova YV, Denisov IG and Sligar SG (2010) Engineering extended membrane scaffold proteins for self-assembly of soluble nanoscale lipid bilayers. Protein engineering, design \& selection 23, 843-848.

Gu J, Wu M, Guo R, Yan K, Lei J, Gao N and Yang M (2016) The architecture of the mammalian respirasome. Nature 537, 639-643.

Guan C, Niu Y, Chen S-C, Kang Y, Wu J-X, Nishi K, Chang CCY, Chang T-Y, Luo T and Chen L (2020) Structural insights into the inhibition mechanism of human sterol O-acyltransferase 1 by a competitive inhibitor. Nature Communications 11, 2478.

Guo YR and MacKinnon R (2017) Structure-based membrane dome mechanism for Piezo mechanosensitivity. eLife 6, e33660.

Hauer F, Gerle C, Fischer N, Oshima A, Shinzawa-Itoh K, Shimada S, Yokoyama K, Fujiyoshi Y and Stark H (2015) GraDeR: Membrane Protein Complex Preparation for Single-Particle Cryo-EM. Structure 23, 1769-1775. 
Hays FA, Roe-Zurz Z and Stroud RM (2010) Overexpression and purification of integral membrane proteins in yeast. Methods in Enzymology 470, 695-707.

Henderson R (1995) The potential and limitations of neutrons, electrons and X-rays for atomic resolution microscopy of unstained biological molecules. Quarterly Reviews of Biophysics 28, 171-193.

Henderson R, Baldwin JM, Ceska TA, Zemlin F, Beckmann E and Downing KH (1990) Model for the structure of bacteriorhodopsin based on high-resolution electron cryo-microscopy. Journal of Molecular Biology 213, 899-929.

Henderson R and Unwin PNT (1975) Three-dimensional model of purple membrane obtained by electron microscopy. Nature 257, 28-32.

Higgins AJ, Flynn AJ, Marconnet A, Musgrove LJ, Postis VLG, Lippiat JD, Chung C, Ceska T, Zoonens M, Sobott F and Muench SP Cycloalkane-modified amphiphilic polymers provide direct extraction of membrane proteins for CryoEM analysis. Submitted for publication. DOI: 10.21203/rs.3.rs-131488/v1

Hovers J, Potschies M, Polidori A, Pucci B, Raynal S, Bonneté F, Serrano-Vega $M$, Tate C, Picot D, Pierre Y, Popot J-L, Nehmé R, Bidet M, Mus-Veteau I, Bußkamp H, Jung K-H, Marx A, Timmins PA and Welte W (2011) A class of mild surfactants that keep integral membrane proteins water-soluble for functional studies and crystallization. Molecular Membrane Biology 28, 171-181.

https://blanco.biomol.uci.edu/mpstruc/

Hua T, Li X, Wu L, Iliopoulos-Tsoutsouvas C, Wang Y, Wu M, Shen L, Johnston CA, Nikas SP, Song F, Song X, Yuan S, Sun Q, Wu Y, Jiang S, Grim TW, Benchama O, Stahl EL, Zvonok N, Zhao S, Bohn LM, Makriyannis A and Liu Z-J (2020) Activation and Signaling Mechanism Revealed by Cannabinoid Receptor-Gi Complex Structures. Cell 180, 655-665.e18.

Huang W, Masureel M, Qu Q, Janetzko J, Inoue A, Kato HE, Robertson MJ, Nguyen KC, Glenn JS, Skiniotis G and Kobilka BK (2020a) Structure of the neurotensin receptor 1 in complex with $\beta$-arrestin 1. Nature 579, 303-308

Huang Y, Wang X, Lv G, Razavi AM, Huysmans GHM, Weinstein H, Bracken C, Eliezer D and Boudker O (2020b) Use of paramagnetic $19 F$ NMR to monitor domain movement in a glutamate transporter homolog. Nature Chemical Biology 16, 1006-1012.

Ishchenko A, Abola EE and Cherezov V (2017) Crystallization of Membrane Proteins: An Overview. Methods in Molecular Biology 1607, 117-141.

Itskanov S and Park E (2019) Structure of the posttranslational Sec protein-translocation channel complex from yeast. Science 363, 84-87.

Jin Q, Zhang B, Zheng X, Li N, Xu L, Xie Y, Song F, Bhat EA, Chen Y, Gao N, Guo J, Zhang X and Ye S (2020) Cryo-EM structures of human pannexin 1 channel. Cell Research 30,449-451.

Johnson S, Fong YH, Deme JC, Furlong EJ, Kuhlen L and Lea SM (2020) Symmetry mismatch in the MS-ring of the bacterial flagellar rotor explains the structural coordination of secretion and rotation. Nature Microbiology 5, 966-975.

Johnson ZL and Chen J (2018) ATP Binding Enables Substrate Release from Multidrug Resistance Protein 1. Cell 172, 81-89.e10.

Jojoa-Cruz S, Saotome K, Murthy SE, Tsui CCA, Sansom MS, Patapoutian A and Ward AB (2018) Cryo-EM structure of the mechanically activated ion channel OSCA1.2. eLife 7, e41845.
Kalienkova V, Clerico Mosina V, Bryner L, Oostergetel GT, Dutzler R and Paulino C (2019) Stepwise activation mechanism of the scramblase nhTMEM16 revealed by cryo-EM. eLife 8, e44364.

Kampjut D and Sazanov LA (2019) Structure and mechanism of mitochondrial proton-translocating transhydrogenase. Nature 573, 291295

Kampjut D and Sazanov LA (2020) The coupling mechanism of mammalian respiratory complex I. Science $\mathbf{3 7 0}$, eabc4209.

Kater L, Frieg B, Berninghausen O, Gohlke H, Beckmann R and Kedrov A (2019) Partially inserted nascent chain unzips the lateral gate of the Sec translocon. EMBO reports 20, e48191.

Khelashvili G, Falzone ME, Cheng X, Lee B-C, Accardi A and Weinstein $H$ (2019) Dynamic modulation of the lipid translocation groove generates a conductive ion channel in $\mathrm{Ca}^{2+}$-bound nhTMEM16. $\mathrm{Na}$ ture Communications 10, 1-15.

Kim JJ, Gharpure A, Teng J, Zhuang Y, Howard RJ, Zhu S, Noviello CM, Walsh RM, Lindahl E and Hibbs RE (2020a) Shared structural mechanisms of general anaesthetics and benzodiazepines. Nature $\mathbf{5 8 5}, 303-308$.

Kim Y, Jeong E, Jeong J-H, Kim Y and Cho Y (2020b) Structural Basis for Activation of the Heterodimeric GABAB Receptor. Journal of Molecular Biology 432, 5966-5984.

Kishikawa J-I, Nakanishi A, Furuta A, Kato T, Namba K, Tamakoshi M, Mitsuoka K and Yokoyama K (2020) Mechanical inhibition of isolated $\mathrm{V}_{\mathrm{o}}$ from V/A-ATPase for proton conductance. eLife $\mathbf{9}$, e56862

Knowles TJ, Finka R, Smith C, Lin Y-P, Dafforn T and Overduin M (2009) Membrane proteins solubilized intact in lipid containing nanoparticles bounded by styrene maleic acid copolymer. Journal of the American Chemical Society 131, 7484-7485.

Koehl A, Hu H, Feng D, Sun B, Zhang Y, Robertson MJ, Chu M, Kobilka TS, Laeremans T, Steyaert J, Tarrasch J, Dutta S, Fonseca R, Weis WI, Mathiesen JM, Skiniotis G and Kobilka BK (2019) Structural insights into the activation of metabotropic glutamate receptors. Nature 566, 79-84.

Kühlbrandt W (2013) Introduction to electron crystallography. Methods in Molecular Biology 955, 1-16.

Kuhlen L, Johnson S, Zeitler A, Bäurle S, Deme JC, Caesar JJE, Debo R, Fisher J, Wagner S and Lea SM (2020) The substrate specificity switch FlhB assembles onto the export gate to regulate type three secretion. Nature Communications 11, 1296.

Kun E, Kirsten E and Piper WN (1979) Stabilization of mitochondrial functions with digitonin. Methods in Enzymology 55, 115-118.

Lauber F, Deme JC, Lea SM and Berks BC (2018) Type 9 secretion system structures reveal a new protein transport mechanism. Nature $\mathbf{5 6 4}, 77-82$.

Le Bon C, Della Pia EA, Giusti F, Lloret N, Zoonens M, Martinez KL and Popot J-L (2014) Synthesis of an oligonucleotide-derivatized amphipol and its use to trap and immobilize membrane proteins. $\mathrm{Nu}$ cleic Acids Research 42, e83.

Le Bon C, Marconnet A, Masscheleyn S, Popot J-L and Zoonens M (2018) Folding and stabilizing membrane proteins in amphipol A835. Methods 147, 95-105. 
Letts JA, Fiedorczuk K, Degliesposti G, Skehel M and Sazanov LA (2019) Structures of Respiratory Supercomplex I+ $\mathrm{III}_{2}$ Reveal Functional and Conformational Crosstalk. Molecular Cell 75, 11311146.e6.

Letts JA, Fiedorczuk K and Sazanov LA (2016) The architecture of respiratory supercomplexes. Nature 537, 644-648.

Li J, Richards MR, Bagal D, Campuzano IDG, Kitova EN, Xiong ZJ, Privé GG and Klassen JS (2016) Characterizing the size and composition of saposin A lipoprotein picodiscs. Analytical Chemistry 88, 9524-9531.

Liang Y-L, Khoshouei M, Radjainia M, Zhang Y, Glukhova A, Tarrasch J, Thal DM, Furness SGB, Christopoulos G, Coudrat T, Danev R, Baumeister W, Miller LJ, Christopoulos A, Kobilka BK, Wootten D, Skiniotis G and Sexton PM (2017) Phase-plate cryo-EM structure of a class B GPCR-G-protein complex. Nature 546, 118-123.

Liao M, Cao E, Julius D and Cheng Y (2013) Structure of the TRPV1 ion channel determined by electron cryo-microscopy. Nature 504, $107-112$.

Linsky TW, Vergara R, Codina N, Nelson JW, Walker MJ, Su W, Barnes CO, Hsiang T-Y, Esser-Nobis K, Yu K, Reneer ZB, Hou YJ, Priya T, Mitsumoto M, Pong A, Lau UY, Mason ML, Chen J, Chen A, Berrocal T, Peng H, Clairmont NS, Castellanos J, Lin Y-R, Josephson-Day A, Baric RS, Fuller DH, Walkey CD, Ross TM, Swanson R, Bjorkman PJ, Gale M, Blancas-Mejia LM, Yen H-L and Silva D-A (2020) De novo design of potent and resilient hACE2 decoys to neutralize SARS-CoV-2. Science 370, 1208-1214.

Liu F, Zhang Z, Csanády L, Gadsby DC and Chen J (2017) Molecular Structure of the Human CFTR Ion Channel. Cell 169, 85-95.e8.

Liu F, Zhang Z, Levit A, Levring J, Touhara KK, Shoichet BK and Chen J (2019a) Structural identification of a hotspot on CFTR for potentiation. Science 364, 1184-1188.

Liu S, Chang S, Han B, Xu L, Zhang M, Zhao C, Yang W, Wang F, Li J, Delpire E, Ye S, Bai X-C and Guo J (2019b) Cryo-EM structures of the human cation-chloride cotransporter KCC1. Science 366, 505508 .

Liu J, Wan F, Jin Q, Li X, Bhat EA, Guo J, Lei M, Guan F, Wu J and Ye S (2020) Cryo-EM structures of human calcium homeostasis modulator 5. Cell Discovery 6, 1-4.

Llaguno MC, Xu H, Shi L, Huang N, Zhang H, Liu Q and Jiang Q-X (2014) Chemically functionalized carbon films for single molecule imaging. Journal of Structural Biology 185, 405-417.

Lopez-Redondo ML, Coudray N, Zhang Z, Alexopoulos J and Stokes DL (2018) Structural basis for the alternating access mechanism of the cation diffusion facilitator YiiP. Proceedings of the National Academy of Sciences of the United States of America 115, 30423047.

Lu P, Bai X-C, Ma D, Xie T, Yan C, Sun L, Yang G, Zhao Y, Zhou R, Scheres SHW and Shi Y (2014) Three-dimensional structure of human $\gamma$-secretase. Nature 512, 166-170.

Ma S, Shen Q, Zhao L-H, Mao C, Zhou XE, Shen D-D, de Waal PW, Bi P, Li C, Jiang Y, Wang M-W, Sexton PM, Wootten D, Melcher $\mathrm{K}$, Zhang Y and Xu HE (2020) Molecular Basis for Hormone Recognition and Activation of Corticotropin-Releasing Factor Receptors. Molecular Cell 77, 669-680.e4.

Maeda S, Yamamoto H, Kinch LN, Garza CM, Takahashi S, Otomo C, Grishin NV, Forli S, Mizushima N and Otomo T (2020) Structure, lipid scrambling activity and role in autophagosome formation of ATG9A. Nature Structural \& Molecular Biology 27, 1194-1201.

Magnani F, Shibata Y, Serrano-Vega MJ and Tate CG (2008) Coevolving stability and conformational homogeneity of the human adenosine A2a receptor. Proceedings of the National Academy of Sciences of the United States of America 105, 10744-10749.

Maldonado M, Padavannil A, Zhou L, Guo F and Letts JA (2020) Atomic structure of a mitochondrial complex I intermediate from vascular plants. eLife 9, e56664.

Marconnet A, Michon B, Le Bon C, Giusti F, Tribet C and Zoonens M (2020) Solubilization and Stabilization of Membrane Proteins by $\mathrm{Cy}-$ cloalkane-Modified Amphiphilic Polymers. Biomacromolecules 21 , 3459-3467.

Martin TG, Bharat TAM, Joerger AC, Bai X-C, Praetorius F, Fersht AR, Dietz H and Scheres SHW (2016) Design of a molecular support for cryo-EM structure determination. Proceedings of the National Academy of Sciences of the United States of America 113, e7456e7463.

Martin-Garcia JM, Conrad CE, Coe J, Roy-Chowdhury S and Fromme P (2016) Serial femtosecond crystallography: A revolution in structural biology. Archives of Biochemistry and Biophysics 602, 32-47.

McCullough J, Clippinger AK, Talledge N, Skowyra ML, Saunders MG, Naismith TV, Colf LA, Afonine P, Arthur C, Sundquist WI, Hanson PI and Frost A (2015) Structure and membrane remodeling activity of ESCRT-III helical polymers. Science 350, 1548-1551.

McDowell MA, Heimes M, Fiorentino F, Mehmood S, Farkas Á, CoyVergara J, Wu D, Bolla JR, Schmid V, Heinze R, Wild K, Flemming D, Pfeffer S, Schwappach B, Robinson CV and Sinning I (2020) Structural Basis of Tail-Anchored Membrane Protein Biogenesis by the GET Insertase Complex. Molecular Cell 80, 72-86.e7.

McGoldrick LL, Singh AK, Demirkhanyan L, Lin T-Y, Casner RG, Zakharian E and Sobolevsky AI (2019) Structure of the thermo-sensitive TRP channel TRP1 from the alga Chlamydomonas reinhardtii. Nature Communications 10, 4180 .

McGoldrick LL, Singh AK, Saotome K, Yelshanskaya MV, Twomey EC, Grassucci RA and Sobolevsky AI (2018) Opening of the human epithelial calcium channel TRPV6. Nature 553, 233-237.

Meyerson JR, Rao P, Kumar J, Chittori S, Banerjee S, Pierson J, Mayer ML and Subramaniam S (2014) Self-assembled monolayers improve protein distribution on holey carbon cryo-EM supports. Scientific Reports 4, 7084 .

Mio K and Sato C (2018) Lipid environment of membrane proteins in cryo-EM based structural analysis. Biophysical Reviews 10, 307316

Nagy JK, Kuhn Hoffmann A, Keyes MH, Gray DN, Oxenoid K and Sanders CR (2001) Use of amphipathic polymers to deliver a membrane protein to lipid bilayers. FEBS letters 501, 115-120.

Nakane T, Kotecha A, Sente A, McMullan G, Masiulis S, Brown PMGE, Grigoras IT, Malinauskaite L, Malinauskas T, Miehling J, Uchański T, Yu L, Karia D, Pechnikova EV, de Jong E, Keizer J, Bischoff M, McCormack J, Tiemeijer P, Hardwick SW, Chirgadze DY, Murshudov G, Aricescu AR and Scheres SHW (2020) Singleparticle cryo-EM at atomic resolution. Nature 587, 152-156.

Nannenga BL and Gonen T (2019) The cryo-EM method microcrystal electron diffraction (MicroED). Nature Methods 16, 369-379. 
Nasr ML, Baptista D, Strauss M, Sun ZJ, Grigoriu S, Huser S, Plückthun A, Hagn F, Walz T, Hogle JM and Wagner G (2017) Covalently circularized nanodiscs for studying membrane proteins and viral entry. Nature Methods 14, 49-52.

Nasr ML and Wagner G (2018) Covalently circularized nanodiscs; challenges and applications. Current Opinion in Structural Biology 51, 129-134.

Nguyen AH, Thomsen ARB, Cahill TJ, Huang R, Huang L-Y, Marcink T, Clarke OB, Heissel S, Masoudi A, Ben-Hail D, Samaan F, Dandey VP, Tan YZ, Hong C, Mahoney JP, Triest S, Little J, Chen X, Sunahara R, Steyaert J, Molina H, Yu Z, des Georges A and Lefkowitz RJ (2019) Structure of an endosomal signaling GPCR-G protein- $\beta$-arrestin megacomplex. Nature Structural \& Molecular Biology 26, $1123-1131$

Nguyen C and Gonen T (2020) Beyond protein structure determination with MicroED. Current Opinion in Structural Biology 64, 51-58.

Nguyen NX, Armache J-P, Lee C, Yang Y, Zeng W, Mootha VK, Cheng Y, Bai X-C and Jiang Y (2018) Cryo-EM structure of a fungal mitochondrial calcium uniporter. Nature 559, 570-574.

Niu Y, Tao X, Touhara KK and MacKinnon R (2020) Cryo-EM analysis of $\mathrm{PIP}_{2}$ regulation in mammalian GIRK channels. eLife $\mathbf{9}$ e60552.

Noble AJ, Dandey VP, Wei H, Brasch J, Chase J, Acharya P, Tan YZ, Zhang Z, Kim LY, Scapin G, Rapp M, Eng ET, Rice WJ, Cheng A, Negro CJ, Shapiro L, Kwong PD, Jeruzalmi D, des Georges A, Potter CS and Carragher B (2018) Routine single particle CryoEM sample and grid characterization by tomography. eLife 7, e34257.

Nogales E and Scheres SHW (2015) Cryo-EM: A Unique Tool for the Visualization of Macromolecular Complexity. Molecular Cell 58, 677-689.

Nwanochie E and Uversky VN (2019) Structure Determination by Single-Particle Cryo-Electron Microscopy: Only the Sky (and Intrinsic Disorder) is the Limit. International Journal of Molecular Sciences 20, 4186

Nygaard R, Kim J and Mancia F (2020) Cryo-electron microscopy analysis of small membrane proteins. Current Opinion in Structural Biology 64, 26-33.

Orwick-Rydmark M, Arnold T and Linke D (2016) The Use of Detergents to Purify Membrane Proteins. Current Protocols in Protein Science 84, 4.8.1-4.8.35.

Otzen DE (2015) Proteins in a brave new surfactant world. Current Opinion in Colloid \& Interface Science 20, 161-169.

Owji AP, Zhao Q, Ji C, Kittredge A, Hopiavuori A, Fu Z, Ward N, Clarke OB, Shen Y, Zhang Y, Hendrickson WA and Yang T (2020) Structural and functional characterization of the bestrophin-2 anion channel. Nature Structural \& Molecular Biology 27, 382-391.

Parey K, Haapanen O, Sharma V, Köfeler H, Züllig T, Prinz S, Siegmund K, Wittig I, Mills DJ, Vonck J, Kühlbrandt W and Zickermann V (2019) High-resolution cryo-EM structures of respiratory complex I: Mechanism, assembly, and disease. Science Advances 5, eaax9484.

Pérez-Pérez R, Lobo-Jarne T, Milenkovic D, Mourier A, Bratic A, García-Bartolomé A, Fernández-Vizarra E, Cadenas S, Delmiro A, García-Consuegra I, Arenas J, Martín MA, Larsson N-G and Ugalde C (2016) COX7A2L Is a Mitochondrial Complex III Binding Protein that Stabilizes the $\mathrm{III}_{2}+\mathrm{IV}$ Supercomplex without Affecting Respirasome Formation. Cell Reports 16, 2387-2398.
Perlmutter JD, Popot J-L and Sachs JN (2014) Molecular Dynamics Simulations of a Membrane Protein/Amphipol Complex. The Journal of Membrane Biology 247, 883-895.

Perry TN, Souabni H, Rapisarda C, Fronzes R, Giusti F, Popot J-L, Zoonens M and Gubellini F (2019) BAmSA: Visualising transmembrane regions in protein complexes using biotinylated amphipols and electron microscopy. Biochimica Et Biophysica Acta. Biomembranes 1861, 466-477.

Picard M, Dahmane T, Garrigos M, Gauron C, Giusti F, le Maire M, Popot J-L and Champeil P (2006) Protective and inhibitory effects of various types of amphipols on the $\mathrm{Ca}^{2+}$-ATPase from sarcoplasmic reticulum: a comparative study. Biochemistry 45, 1861-1869.

Pinke G, Zhou L and Sazanov LA (2020) Cryo-EM structure of the entire mammalian F-type ATP synthase. Nature Structural \& Molecular Biology 27, 1077-1085.

Piton J, Pojer F, Wakatsuki S, Gati C and Cole ST (2020) High resolution CryoEM structure of the ring-shaped virulence factor EspB from Mycobacterium tuberculosis. Journal of Structural Biology X $\mathbf{4}$, 100029.

Pleiner T, Tomaleri GP, Januszyk K, Inglis AJ, Hazu M and Voorhees RM (2020) Structural basis for membrane insertion by the human ER membrane protein complex. Science 369, 433-436.

Pocanschi CL, Popot J-L and Kleinschmidt JH (2013) Folding and stability of outer membrane protein A (OmpA) from Escherichia coli in an amphipathic polymer, amphipol A8-35. European biophysics journal 42, 103-118.

Popot J-L (2018) Membrane Proteins in Aqueous Solutions: From Detergents to Amphipols, New York: Springer.

Popot J-L, Althoff T, Bagnard D, Banères J-L, Bazzacco P, BillonDenis E, Catoire LJ, Champeil P, Charvolin D, Cocco MJ, Crémel G, Dahmane T, de la Maza LM, Ebel C, Gabel F, Giusti F, Gohon Y, Goormaghtigh E, Guittet E, Kleinschmidt JH, Kühlbrandt W, Le Bon C, Martinez KL, Picard M, Pucci B, Sachs JN, Tribet C, van Heijenoort C, Wien F, Zito F and Zoonens M (2011) Amphipols from A to Z. Annual Review of Biophysics 40, 379-408.

Qian H, Wu X, Du X, Yao X, Zhao X, Lee J, Yang H and Yan N (2020) Structural Basis of Low-pH-Dependent Lysosomal Cholesterol Egress by NPC1 and NPC2. Cell 182, 98-111.e18.

Qiao A, Han S, Li X, Li Z, Zhao P, Dai A, Chang R, Tai L, Tan Q, Chu X, Ma L, Thorsen TS, Reedtz-Runge S, Yang D, Wang M-W, Sexton PM, Wootten D, Sun F, Zhao Q and Wu B (2020) Structural basis of Gs and Gi recognition by the human glucagon receptor. Science $\mathbf{3 6 7}$, $1346-1352$.

Qiu W, Fu Z, Xu GG, Grassucci RA, Zhang Y, Frank J, Hendrickson WA and Guo Y (2018) Structure and activity of lipid bilayer within a membrane-protein transporter. Proceedings of the National Academy of Sciences of the United States of America 115, 12985-12990.

Rahman MM, Teng J, Worrell BT, Noviello CM, Lee M, Karlin A, Stowell MHB and Hibbs RE (2020) Structure of the Native Muscletype Nicotinic Receptor and Inhibition by Snake Venom Toxins. Neuron 106, 952-962.e5.

Ravelli RBG, Nijpels FJT, Henderikx RJM, Weissenberger G, Thewessem S, Gijsbers A, Beulen BWAMM, López-Iglesias C and Peters PJ (2020) Cryo-EM structures from sub-nl volumes using pinprinting and jet vitrification. Nature Communications 11, 2563. 
Razinkov I, Dandey V, Wei H, Zhang Z, Melnekoff D, Rice WJ, Wigge C, Potter CS and Carragher B (2016) A new method for vitrifying samples for cryoEM. Journal of Structural Biology 195, 190-198.

Reddy B, Bavi N, Lu A, Park Y and Perozo E (2019) Molecular basis of force-from-lipids gating in the mechanosensitive channel $\mathrm{MscS}$. eLife 8, e50486.

Righetto RD, Biyani N, Kowal J, Chami M and Stahlberg H (2019) Retrieving high-resolution information from disordered 2D crystals by single-particle cryo-EM. Nature Communications 10,1722.

Roh S-H, Shekhar M, Pintilie G, Chipot C, Wilkens S, Singharoy A and Chiu W (2020) Cryo-EM and MD infer water-mediated proton transport and autoinhibition mechanisms of $\mathrm{V}_{\mathrm{o}}$ complex. Science Advances $\mathbf{6}$, eabb9605.

Roh S-H, Stam NJ, Hryc CF, Couoh-Cardel S, Pintilie G, Chiu W and Wilkens S (2018) The 3.5-Å CryoEM Structure of Nanodisc-Reconstituted Yeast Vacuolar ATPase Vo Proton Channel. Molecular Cell 69, 993-1004.e3.

Rosevear P, VanAken T, Baxter J and Ferguson-Miller S (1980) Alkyl glycoside detergents: a simpler synthesis and their effects on kinetic and physical properties of cytochrome c oxidase. Biochemistry 19, $4108-4115$

Ruan Z, Orozco IJ, Du J and Lü W (2020a) Structures of human pannexin 1 reveal ion pathways and mechanism of gating. Nature 584, 646-651.

Ruan Z, Osei-Owusu J, Du J, Qiu Z and Lü W (2020b) Structures and $\mathrm{pH}$-sensing mechanism of the proton-activated chloride channel. $\mathrm{Na}$ ture 588, 350-354.

Russo CJ and Passmore LA (2014) Ultrastable gold substrates for electron cryomicroscopy. Science 346, 1377-1380.

Sadaf A, Cho KH, Byrne B and Chae PS (2015) Amphipathic agents for membrane protein study. Methods in Enzymology 557, 57-94.

Sauer DB, Trebesch N, Marden JJ, Cocco N, Song J, Koide A, Koide S, Tajkhorshid E and Wang D-N (2020) Structural basis for the reaction cycle of DASS dicarboxylate transporters. eLife 9, e61350.

Schmidli C, Albiez S, Rima L, Righetto R, Mohammed I, Oliva P, Kovacik L, Stahlberg H and Braun T (2019) Microfluidic protein isolation and sample preparation for high-resolution cryo-EM. Proceedings of the National Academy of Sciences of the United States of America 116, 15007-15012.

Sgro GG and Costa TRD (2018) Cryo-EM Grid Preparation of Membrane Protein Samples for Single Particle Analysis. Frontiers in Molecular Biosciences 5, 74 .

Shen H, Li Z, Jiang Y, Pan X, Wu J, Cristofori-Armstrong B, Smith JJ, Chin YKY, Lei J, Zhou Q, King GF and Yan N (2018) Structural basis for the modulation of voltage-gated sodium channels by animal toxins. Science 362, eaau2596.

Shen PS, Yang X, DeCaen PG, Liu X, Bulkley D, Clapham DE and Cao E (2016) The Structure of the Polycystic Kidney Disease Channel PKD2 in Lipid Nanodiscs. Cell 167, 763-773.e11.

Shih AY, Denisov IG, Phillips JC, Sligar SG and Schulten K (2005) Molecular dynamics simulations of discoidal bilayers assembled from truncated human lipoproteins. Biophys. J. 88, 548-556.
Singh AK, McGoldrick LL and Sobolevsky AI (2018) Structure and gating mechanism of the transient receptor potential channel TRPV3. Nature Structural \& Molecular Biology 25, 805-813.

Sligar SG and Denisov IG (2020) Nanodiscs: A Toolkit for Membrane Protein Science. Protein Science 30, 297-315.

Sousa JS, Mills DJ, Vonck J and Kühlbrandt W (2016) Functional asymmetry and electron flow in the bovine respirasome. eLIFE $\mathbf{5}$, e21290.

Srivastava AP, Luo M, Zhou W, Symersky J, Bai D, Chambers MG, Faraldo-Gómez JD, Liao M and Mueller DM (2018) High-resolution cryo-EM analysis of the yeast ATP synthase in a lipid membrane. Science 360, eaas 9699.

Stetsenko A and Guskov A (2017) An Overview of the Top Ten Detergents Used for Membrane Protein Crystallization. Crystals 7, 197.

Stroud Z, Hall SCL and Dafforn TR (2018) Purification of membrane proteins free from conventional detergents: SMA, new polymers, new opportunities and new insights. Methods (San Diego, Calif.) 147, 106-117.

Sui X, Arlt H, Brock KP, Lai ZW, DiMaio F, Marks DS, Liao M, Farese RV and Walther TC (2018) Cryo-electron microscopy structure of the lipid droplet-formation protein seipin. The Journal of Cell Biology 217, 4080-4091.

Sun C, Benlekbir S, Venkatakrishnan P, Wang Y, Hong S, Hosler J, Tajkhorshid E, Rubinstein JL and Gennis RB (2018) Structure of the alternative complex III in a supercomplex with cytochrome oxidase. Nature 557, 123-126.

Sun J and MacKinnon R (2020) Structural Basis of Human KCNQ1 Modulation and Gating. Cell 180, 340-347.e9.

Sverzhinsky A, Qian S, Yang L, Allaire M, Moraes I, Ma D, Chung JW, Zoonens M, Popot J-L and Coulton JW (2014) AmphipolTrapped ExbB-ExbD Membrane Protein Complex from Escherichia coli: A Biochemical and Structural Case Study. The Journal of Membrane Biology 247, 1005-1018.

Tao X and MacKinnon R (2019) Molecular structures of the human Slo1 $\mathrm{K}^{+}$channel in complex with $\beta 4$. eLife $\mathbf{8}$, e51409.

Tascón I, Sousa JS, Corey RA, Mills DJ, Griwatz D, Aumüller N, Mikusevic V, Stansfeld PJ, Vonck J and Hänelt I (2020) Structural basis of proton-coupled potassium transport in the KUP family. $\mathrm{Na}$ ture Communications 11, 626.

Tate CG (2010) Practical Considerations of Membrane Protein Instability during Purification and Crystallisation. Heterologous Expression of Membrane Proteins: Methods and Protocols. In (I. MusVeteau, ed.), Methods in Molecular Biology. pp.187-203. Totowa, NJ: Humana Press.

Thompson AA, Liu JJ, Chun E, Wacker D, Wu H, Cherezov V and Stevens RC (2011) GPCR stabilization using the bicelle-like architecture of mixed sterol-detergent micelles. Methods (San Diego, Calif.) 55, 310-317.

Tonggu L and Wang L (2018) Broken Symmetry in the Human BK Channel, bioRxiv.

Tonggu L and Wang L (2020) Cryo-EM sample preparation method for extremely low concentration liposomes. Ultramicroscopy 208, 112849. 
Tribet C, Audebert R and Popot J-L (1996) Amphipols: Polymers that keep membrane proteins soluble in aqueous solutions. Proceedings of the National Academy of Sciences 93, 15047-15050.

Tsai C-J, Marino J, Adaixo R, Pamula F, Muehle J, Maeda S, Flock T, Taylor NM, Mohammed I, Matile H, Dawson RJ, Deupi X, Stahlberg $\mathrm{H}$ and Schertler G (2019) Cryo-EM structure of the rhodopsin-Gai$\beta \gamma$ complex reveals binding of the rhodopsin $\mathrm{C}$-terminal tail to the $\mathrm{g} \beta$ subunit. eLife $\mathbf{8}$, e46041.

Tsutsumi N, Mukherjee S, Waghray D, Janda CY, Jude KM, Miao Y, Burg JS, Aduri NG, Kossiakoff AA, Gati C and Garcia KC (2020) Structure of human Frizzled5 by fiducial-assisted cryo-EM supports a heterodimeric mechanism of canonical Wnt signaling. eLife $\mathbf{9}$, e58464.

Tucker K and Park E (2019) Cryo-EM structure of the mitochondrial protein-import channel TOM complex at near-atomic resolution. $\mathrm{Na}$ ture Structural \& Molecular Biology 26, 1158-1166.

Uchański T, Masiulis S, Fischer B, Kalichuk V, López-Sánchez U, Zarkadas E, Weckener M, Sente A, Ward P, Wohlkönig A, Zögg T, Remaut H, Naismith JH, Nury H, Vranken W, Aricescu AR, Pardon E and Steyaert J (2021) Megabodies expand the nanobody toolkit for protein structure determination by single-particle cryo-EM. Nature Methods 18, 60-68.

Vinayagam D, Quentin D, Yu-Strzelczyk J, Sitsel O, Merino F, Stabrin M, Hofnagel O, Yu M, Ledeboer MW, Nagel G, Malojcic G and Raunser S (2020) Structural basis of TRPC4 regulation by calmodulin and pharmacological agents. eLife $\mathbf{9}$, e60603.

Vinothkumar KR and Henderson R (2016) Single particle electron cryomicroscopy: trends, issues and future perspective. Quarterly Reviews of Biophysics $\mathbf{4 9}, \mathrm{e} 13$.

Walter JD, Sawicka M and Dutzler R (2019) Cryo-EM structures and functional characterization of murine Slc26a9 reveal mechanism of uncoupled chloride transport. eLife $\mathbf{8}$, e46986.

Wang K, Preisler SS, Zhang L, Cui Y, Missel JW, Grønberg C, Gotfryd K, Lindahl E, Andersson M, Calloe K, Egea PF, Klaerke DA, Pusch M, Pedersen PA, Zhou ZH and Gourdon P (2019) Structure of the human ClC-1 chloride channel. PLOS Biology 17, e3000218.

Wang L and Sigworth FJ (2009) Structure of the BK potassium channel in a lipid membrane from electron cryomicroscopy. Nature 461, 292 295.

Wang L and Sigworth FJ (2010) Liposomes on a streptavidin crystal: a system to study membrane proteins by cryo-EM. Methods in Enzymology 481, 147-164.

Wang X and Boudker O (2020) Large domain movements through the lipid bilayer mediate substrate release and inhibition of glutamate transporters. eLife 9, e58417.

Wang L, Johnson ZL, Wasserman MR, Levring J, Chen J and Liu S (2020a) Characterization of the kinetic cycle of an ABC transporter by single-molecule and cryo-EM analyses. eLife $\mathbf{9}$, e56451.

Wang Z, Hu W and Zheng H (2020b) Pathogenic siderophore ABC importer YbtPQ adopts a surprising fold of exporter. Science Advances $\mathbf{6}$, eaay7997.

Wasilko DJ, Johnson ZL, Ammirati M, Che Y, Griffor MC, Han S and Wu H (2020) Structural basis for chemokine receptor CCR6 activation by the endogenous protein ligand CCL20. Nature Communications 11, 3031 .
Weiss HM and Grisshammer R (2002) Purification and characterization of the human adenosine $\mathrm{A}(2 \mathrm{a})$ receptor functionally expressed in Escherichia coli. European Journal of Biochemistry 269, 82-92.

Weiss MS, Wacker T, Weckesser J, Weite W and Schulz GE (1990) The three-dimensional structure of porin from Rhodobacter capsulatus at 3 Å resolution. FEBS Letters 267, 268-272.

Willegems K and Efremov RG (2018) Influence of Lipid Mimetics on Gating of Ryanodine Receptor. Structure 26, 1303-1313.e4.

Wu M, Gu J, Guo R, Huang Y and Yang M (2016) Structure of Mammalian Respiratory Supercomplex $\mathrm{I}_{1} \mathrm{III}_{2} \mathrm{IV}_{1}$. Cell 167, 15981609.e10.

Wu S, Avila-Sakar A, Kim J, Booth DS, Greenberg CH, Rossi A, Liao M, Li X, Alian A, Griner SL, Juge N, Yu Y, Mergel CM, ChaparroRiggers J, Strop P, Tampé R, Edwards RH, Stroud RM, Craik CS and Cheng Y (2012) Fabs enable single particle cryoEM studies of small proteins. Structure 20, 582-592.

Wu X, Cabanos C and Rapoport TA (2019) Structure of the post-translational protein translocation machinery of the ER membrane. Nature 566, 136-139.

Wu X, Siggel M, Ovchinnikov S, Mi W, Svetlov V, Nudler E, Liao M, Hummer G and Rapoport TA (2020) Structural basis of ERassociated protein degradation mediated by the Hrd1 ubiquitin ligase complex. Science $\mathbf{3 6 8}$, eaaz2449.

Yan R, Zhao X, Lei J and Zhou Q (2019) Structure of the human LAT1$4 \mathrm{~F} 2 \mathrm{hc}$ heteromeric amino acid transporter complex. Nature $\mathbf{5 6 8}$, $127-130$.

Yang G, Zhou R, Zhou Q, Guo X, Yan C, Ke M, Lei J and Shi Y (2019) Structural basis of Notch recognition by human $\gamma$-secretase. Nature $\mathbf{5 6 5}, 192-197$.

Yao X, Fan X and Yan N (2020) Cryo-EM analysis of a membrane protein embedded in the liposome. Proceedings of the National Academy of Sciences 117, 18497-18503.

Yin J, Chen K-YM, Clark MJ, Hijazi M, Kumari P, Bai X-C, Sunahara RK, Barth P and Rosenbaum DM (2020) Structure of a D2 dopamine receptor-G-protein complex in a lipid membrane. Nature 584, 125129

Yin W, Li Z, Jin M, Yin Y-L, de Waal PW, Pal K, Yin Y, Gao X, He Y, Gao J, Wang X, Zhang Y, Zhou H, Melcher K, Jiang Y, Cong Y, Edward Zhou X, Yu X and Eric Xu H (2019a) A complex structure of arrestin-2 bound to a $\mathrm{G}$ protein-coupled receptor. Cell Research 29, 971-983.

Yin Y, Wu M, Hsu AL, Borschel WF, Borgnia MJ, Lander GC and Lee S-Y (2019b) Visualizing structural transitions of ligand-dependent gating of the TRPM2 channel. Nature Communications 10, 1-14.

Yoder N and Gouaux E (2020) The His-Gly motif of acid-sensing ion channels resides in a reentrant "loop" implicated in gating and ion selectivity. eLife 9, e56527.

Yoo J, Wu M, Yin Y, Herzik MA, Lander GC and Lee S-Y (2018) Cryo-EM structure of a mitochondrial calcium uniporter. Science 361, 506-511.

Yu X, Plotnikova O, Bonin PD, Subashi TA, McLellan TJ, Dumlao D, Che Y, Dong YY, Carpenter EP, West GM, Qiu X, Culp JS and Han $S$ (2019) Cryo-EM structures of the human glutamine transporter SLC1A5 (ASCT2) in the outward-facing conformation. eLife $\mathbf{8}$, e48120. 
Zhang Z, Liu F and Chen J (2017) Conformational Changes of CFTR upon Phosphorylation and ATP Binding. Cell 170, 483-491.e8.

Zhang C, Konermann S, Brideau NJ, Lotfy P, Wu X, Novick SJ, Strutzenberg T, Griffin PR, Hsu PD and Lyumkis D (2018a) Structural Basis for the RNA-Guided Ribonuclease Activity of CRISPRCas13d. Cell 175, 212-223.e17.

Zhang Z, Liu F and Chen J (2018b) Molecular structure of the ATPbound, phosphorylated human CFTR. Proceedings of the National Academy of Sciences of the United States of America 115, 1275712762 .

Zhang L, Zhao Y, Gao Y, Wu L, Gao R, Zhang Q, Wang Y, Wu C, Wu F, Gurcha SS, Veerapen N, Batt SM, Zhao W, Qin L, Yang X, Wang M, Zhu Y, Zhang B, Bi L, Zhang X, Yang H, Guddat LW, Xu W, Wang Q, Li J, Besra GS and Rao Z (2020) Structures of cell wall arabinosyltransferases with the anti-tuberculosis drug ethambutol. Science 368, 1211-1219.

Zhao DY, Pöge M, Morizumi T, Gulati S, Van Eps N, Zhang J, Miszta P, Filipek S, Mahamid J, Plitzko JM, Baumeister W, Ernst OP and Palczewski K (2019a) Cryo-EM structure of the native rhodopsin dimer in nanodiscs. The Journal of Biological Chemistry 294, 1421514230 .

Zhao J, Xu H, Carroni M, Lebrette H, Wallden K, Moe A, Matsuoka R, Högbom M and Zou X (2019b) A simple pressure-assisted method for cryo-EM specimen preparation. bioRxiv, 665448 .

Zhao L-H, Ma S, Sutkeviciute I, Shen D-D, Zhou XE, de Waal PW, Li C-Y, Kang Y, Clark LJ, Jean-Alphonse FG, White AD, Yang D, Dai A, Cai X, Chen J, Li C, Jiang Y, Watanabe T, Gardella TJ, Melcher K, Wang M-W, Vilardaga J-P, Xu HE and Zhang Y (2019c) Structure and dynamics of the active human parathyroid hormone receptor-1. Science 364, 148-153.

Zhao Y, Huang G, Wu J, Wu Q, Gao S, Yan Z, Lei J and Yan N (2019d) Molecular Basis for Ligand Modulation of a Mammalian VoltageGated Ca ${ }^{2+}$ Channel. Cell 177, 1495-1506.e12.
Zhao J, Lin King JV, Paulsen CE, Cheng Y and Julius D (2020) Irritantevoked activation and calcium modulation of the TRPA1 receptor. Nature 585, 141-145.

Zheng L, Li Y, Li X, Zhong Q, Li N, Zhang K, Zhang Y, Chu H, Ma C, Li G, Zhao J and Gao N (2019) Structural and functional insights into the tetrameric photosystem I from heterocyst-forming cyanobacteria. Nature Plants 5, 1087-1097.

Zhou R, Yang G, Guo X, Zhou Q, Lei J and Shi Y (2019) Recognition of the amyloid precursor protein by human $\gamma$-secretase. Science $\mathbf{3 6 3}$, eaaw0930.

Zhou X, Li M, Su D, Jia Q, Li H, Li X and Yang J (2017) Cryo-EM structures of the human endolysosomal TRPML3 channel in three distinct states. Nature Structural and Molecular Biology 24, 11461154 .

Zoonens M, Giusti F, Zito F and Popot J-L (2007) Dynamics of membrane protein/amphipol association studied by Förster resonance energy transfer: implications for in vitro studies of amphipol-stabilized membrane proteins. Biochemistry 46, 10392-10404.

Zoonens M and Miroux B (2010) Expression of membrane proteins at the Escherichia coli membrane for structural studies. Methods in Molecular Biology (Clifton, N.J.) 601, 49-66.

Zoonens M and Popot J-L (2014) Amphipols for Each Season. The Journal of Membrane Biology 247, 759-796.

Zubcevic L, Herzik MA, Chung BC, Liu Z, Lander GC and Lee S-Y (2016) Cryo-electron microscopy structure of the TRPV2 ion channel. Nature Structural \& Molecular Biology 23, 180-186.

Zubcevic L, Herzik MA, Wu M, Borschel WF, Hirschi M, Song AS, Lander GC and Lee S-Y (2018) Conformational ensemble of the human TRPV3 ion channel. Nature Communications 9, 1-12.

Zubcevic L, Hsu AL, Borgnia MJ and Lee S-Y (2019) Symmetry transitions during gating of the TRPV2 ion channel in lipid membranes. eLife 8, e45779. 